\title{
A VARIAÇÃO NA ENTOAÇÃO DE DECLARATIVAS NEUTRARS E INTERROGATIVAS TOTAIS NAS TRÊS CAPITAIS DO SUL DO BRASIL
}

\author{
THE VARIATION IN THE INTONATION OF NEUTRAL \\ DECLARATIVE AND TOTAL INTERROGATIVES IN THE THREE \\ CAPITAL CITIES LOCATED IN SOUTHERN BRAZIL
}

\author{
Izabel Christine SEARA ${ }^{1}$ \\ Lurdes de Castro MOUTINHO ${ }^{2}$
}

\begin{abstract}
Resumo: Este estudo, ainda inicial, trata de dados produzidos por falantes das três capitais do Sul do Brasil (florianopolitanos, porto alegrenses e curitibanos). São analisados os padrões entonacionais referentes a sentenças declarativa neutra e interrogativa total. Foram realizados dois experimentos: um de produção e outro de percepção. Os dados de produção foram analisados com base nos parâmetros: sílaba em que se localiza o pico de F0, seu alinhamento na sílaba e as variações de valores de F0 entre declarativas e interrogativas, focalizando as regiões pré-nuclear e nuclear. Os resultados dos experimentos de produção aqui analisados mostraram que há diferenças entre os dados de curitibanos e florianopolitanos e entre os de curitibanos e porto alegrenses. Há também semelhanças entre os dados de Porto Alegre e Florianópolis. Esses resultados foram observados principalmente nas diferenças de valores de F0 (em semitons) entre declarativas e interrogativas de Curitiba em confronto com Florianópolis e Porto Alegre. Testes de percepção confirmaram as diferenças verificadas nos dados acústicos. Apesar de esses resultados se basearem ainda em poucos informantes, eles já mostram uma certa robustez, assinalada pelos resultados objetivos e pelos testes de percepção.
\end{abstract}

Palavras-chave: Prosódia. Falantes de Curitiba, Florianópolis e Porto Alegre. Declarativa neutra. Interrogativa total.
Abstract: This research deals with data produced by speakers from the three capitals of southern Brazil - Florianópolis, Porto Alegre, and Curitiba. It was analyzed the intonational patterns referring to neutral declarative sentences and total interrogative sentences. Two experiments were performed: one for production and one for perception. The production data were analyzed based on the following parameters: the syllable where the F0 peak is located, its syllable alignment, and the variations of F0 values between declarative and interrogative sentences, focusing on the pre-nuclear and nuclear regions. The results showed that there are differences between the data from speakers from Curitiba and Florianópolis; and between the data from speakers from Curitiba and Porto Alegre. There are also similarities between the data from Porto Alegre and Florianópolis. The results were observed mainly in the differences of F0 values (in semitones) between declarative and interrogative sentences from Curitiba in comparison with Florianópolis and Porto Alegre. Perception tests confirmed the differences in acoustic data.

Keywords: Prosody. Speakers from Curitiba. Florianópolis and Porto Alegre. Neutral declarative. Total interrogative. 1 Universidade Federal de Santa Catarina (UFSC), Florianópolis, Santa Catarina, Brasil; izabel.seara@ufsc.br;
https://orcid.org/0000-0001-9204-9730

2 Universidade de Aveiro (UA), Aveiro, Portugal; Imoutinho@ua.pt;

https://orcid.org/0000-0003-0869-9912 
- A variação na entoação de declarativas neutras e interrogativas totais nas três capitais do Sul do Brasil

\section{Introdução}

Diversos estudos de cunho prosódico-entonacional têm sido desenvolvidos sobre dados do português brasileiro e europeu (CUNHA, 2000; MORAES, 2008, 1998; MOUTINHO et al., 2005; MOUTINHO; COIMBRA, 2010; MILAN, 2015; NUNES, 2011, 2015; NUNES; RILLIARD; SEARA, 2015; CRUZ; SEARA; MOUTINHO, 2015; CASTELO; FROTA, 2016; MILAN; KLUGE, 2017a, dentre outros). Muitos deles resultam da participação no Projeto Atlas Multimedia Prosódico das Linguas Românicas - Língua Portuguesa (Projeto AMPER-POR), por exemplo: Moutinho et al. (2005); Moutinho e Coimbra (2010), Nunes (2011, 2015), Milan (2015), Nunes e Seara (2015), Nunes, Rilliard e Seara, 2015, Milan e Kluge (2017b), Moutinho e Seara (2019). Sob os critérios do Projeto AMPER-POR, foram coletados, para o português brasileiro (PB), dados de diferentes capitais (por exemplo, Porto Alegre, Florianópolis, Curitiba, Belém e São Paulo) e, para o português europeu (PE), dados de todas as regiões do continente e, também, dos arquipélagos dos Açores e da Madeira.

Este artigo apresenta os primeiros resultados de uma análise acústico-perceptual exploratória de produções de sentenças declarativas neutras e interrogativas totais coletadas pelo Projeto AMPER-POR referentes a Porto Alegre (RS), trazendo também uma comparação dos resultados apresentados para as três capitais do Sul do Brasil: Porto Alegre (capital do estado do Rio Grande do Sul), Florianópolis (capital do estado de Santa Catarina) e Curitiba (capital do estado do Paraná). O objetivo é investigar o contorno prosódico-entonacional dessas sentenças, a partir da frequência fundamental (F0), considerando-se diferenças e/ou similitudes entre seus valores, localização do pico de F0 e seu alinhamento na sílaba.

Nosso interesse por esses falares se deve à escassez de estudos prosódicos sobre as capitais do Sul do Brasil nos dados provenientes do Projeto AMPER-POR. Além disso, pesquisas comparativas se tornam relevantes para a observação da variação geoprosódica, o principal objetivo do referido projeto. Até aqui, apenas os dados de Curitiba e Florianópolis foram pesquisados com base nos critérios de coleta e análise do Projeto AMPER-POR (SEARA; SILVA; BERRI, 2011; NUNES, 2011; MILAN, 2015; NUNES, 2015; MILAN; KLUGE, 2017a e b), no entanto, não foram observados estudos que investigassem a variação na produção de declarativas neutras e interrogativas totais comparando dados provenientes de falantes de Curitiba (PR), Florianópolis (SC) e Porto Alegre (RS). Por essa razão, buscamos com este estudo responder às seguintes questões de pesquisa: (i) haverá diferenças de declarativas neutras e interrogativas totais entre os falares das três 
capitais aqui estudadas, considerando-se o pré-núcleo e o núcleo entoacional? (ii) testes de percepção (discriminação e identificação) irão ratificar diferenças, caso elas sejam verificadas nos dados analisados?

Nossas hipóteses são de que, quando as diferenças entre os valores de F0 (normalizados em semitons) de declarativas neutras e interrogativas totais e entre os falares forem maiores do que 3 semitons (st), essas diferenças serão ratificadas pelos testes de percepção. Nesse caso, podemos considerar como diferenças de fato. Caso os testes de percepção mostrem diferenças, mas os valores não ultrapassem 3 st, será realizada uma análise acústica detalhada da implementação da curva de F0, considerando a sílaba em que ocorre o pico de F0 e seu alinhamento na sílaba, na tentativa de elucidar o parâmetro que leva os ouvintes a perceberem diferenças.

Em resumo, este estudo é composto por uma análise prosódico-entonacional da produção de declarativas neutras e interrogativas totais e por experimentos perceptuais que visam corroborar os achados dos experimentos de produção.

\section{Algumas palavras sobre a colonização das capitais do Sul do Brasil}

Iniciamos esse breve histórico, a partir da colonização das regiões que aqui analisamos, motivados pela percepção, nas etapas de segmentação e etiquetagem, de semelhanças no nível suprassegmental entre as produções coletadas de falantes de Florianópolis e de Porto Alegre. No nível segmental, são verificados estudos sobre produções de falantes das capitais do sul do Brasil, como, por exemplo, os sons dos róticos (HAUPT; SEARA, 2020; CAMPOS; BROD; SEARA, 2013; BOTASSINI, 2011), as sibilantes em final de sílaba (BIASIBETTI, 2018), a lateral velarizada (BROD, 2014), dentre outras.

As três capitais do Sul do Brasil sofreram influência, principalmente, da colonização europeia: Curitiba por países eslavos, como os poloneses, Florianópolis e Porto Alegre por açorianos. Os mapas mostrados na Figura 1 indicam as regiões dessas colonizações e a localização das capitais nos três estados do Sul do Brasil. 
- A variação na entoação de declarativas neutras e interrogativas totais nas três capitais do Sul do Brasil

Figura 1. Mapas que evidenciam os povos que colonizaram os estados da região Sul do Brasil em que se localizam as três capitais pesquisadas

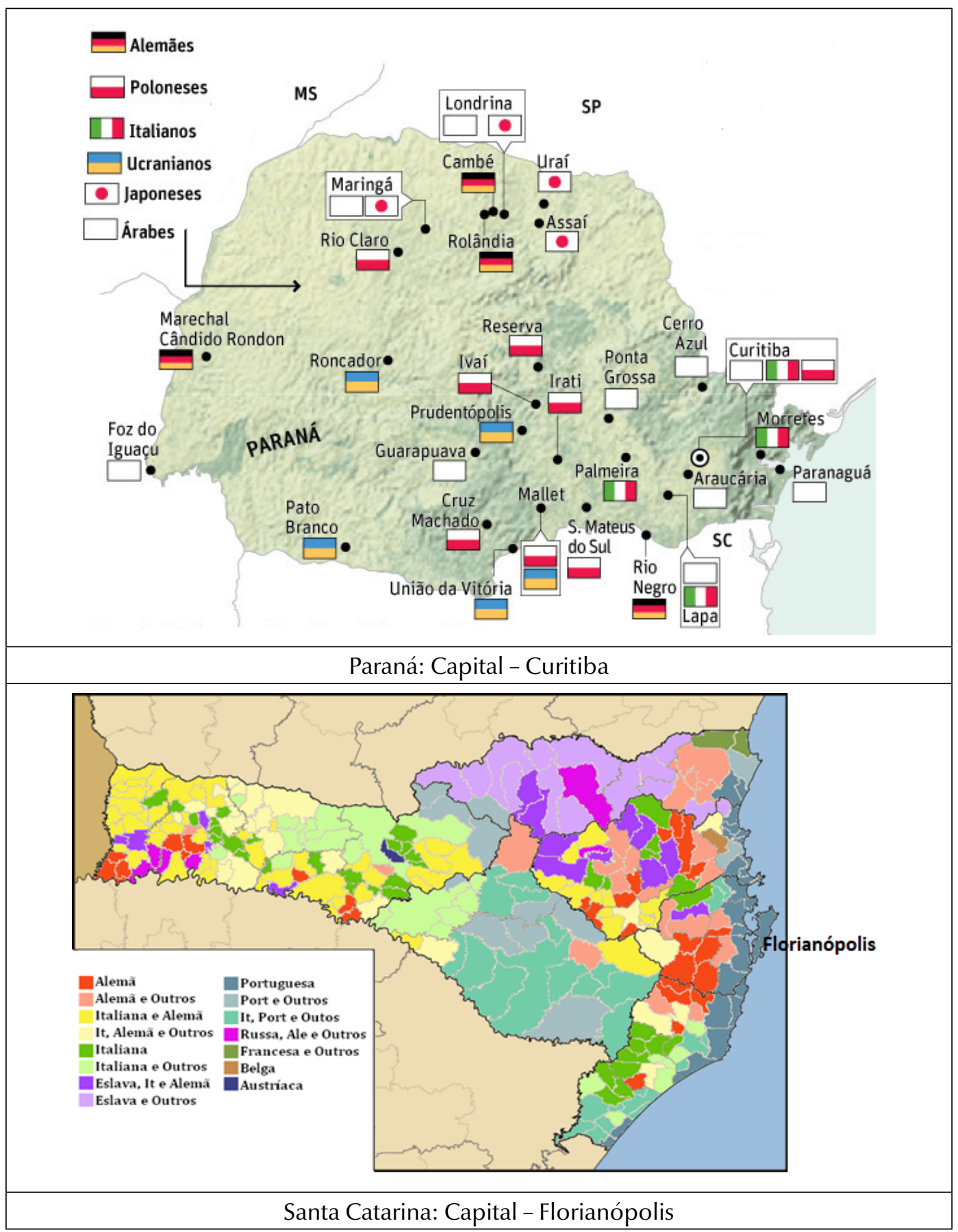




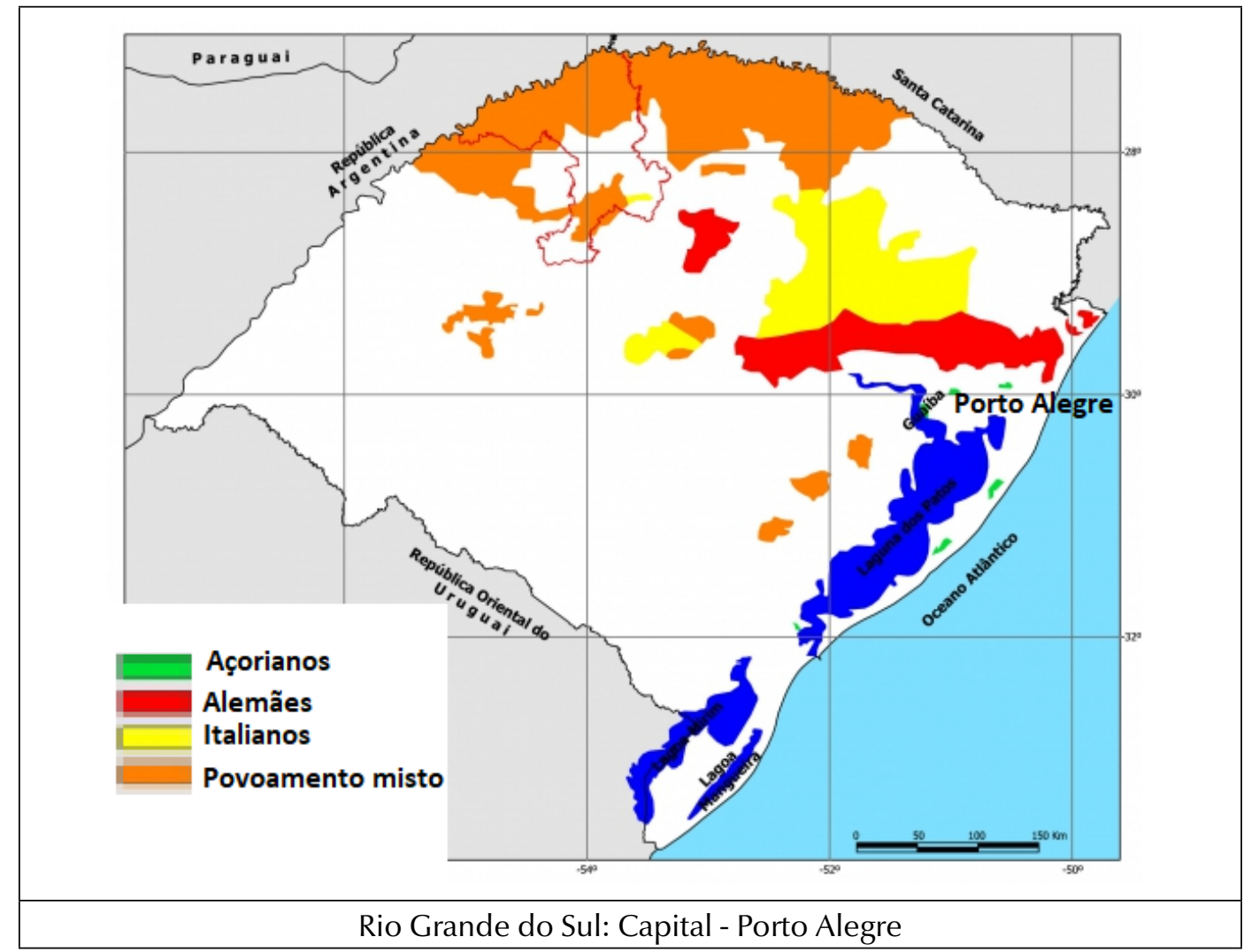

Fonte: Mapas adaptados de https://bit.ly/3jdsWS8; https://bit.ly/34yRDEw;

https://bit.ly/3aYFKc9

Na Figura 1, vê-se que, pelo mapa do Paraná (janela superior), a região de Curitiba revela a colonização eslava, italiana e árabe. No mapa de Santa Catarina (janela central), destacamos a colonização portuguesa, proveniente dos Açores, localizada em todo o seu litoral, incluindo a capital, Florianópolis. No mapa do Rio Grande do Sul (janela inferior), também observamos na região da capital - Porto Alegre - a presença açoriana (FURLAN, 1989; LACERDA, 2013). Para Porto Alegre, vieram, entre 1749 e 1752, 60 casais das Ilhas dos Açores, conforme Laytano (1974 apud FURLAN, 1989), sendo considerada uma das cidades do Rio Grande do Sul fundada com a contribuição açoriana. Para Santa Catarina, foram enviados, entre 1748 e 1756, em torno de 6000 ilhéus, conforme Piazza (1983 apud FURLAN, 1989). A influência açoriana no estado gaúcho é apontada por Furlan (1989), quando diz que o falar açoriano-catarinense se identifica com o falar gaúcho no uso do pronome tu que era empregado pelos açorianos. Entretanto, o autor sugere que as diferenças no nível fonético, apontadas anteriormente, poderiam ser explicadas pelo menor índice de colonizadores açorianos na região de Porto Alegre que foi de $50 \%$ em relação aos nativos, enquanto, em Santa Catarina, o percentual de açorianos em relação aos que ali viviam foi de $144 \%$. 
- A variação na entoação de declarativas neutras e interrogativas totais nas três capitais do Sul do Brasil

Assim, as diferenças, se observadas, podem estar relacionadas às questões de colonização. Alemães, franceses, suíços, italianos, ucranianos e japoneses contribuíram para a formação de Curitiba e, predominantemente, poloneses, que formam hoje a maior colônia polonesa no Brasil. No entanto, para Florianópolis e Porto Alegre, a colonização teve contribuição açoriana, em especial, Florianópolis.

Desse modo, para o presente estudo, iremos comparar dados acústicos referentes a (i) Florianópolis, também já averiguados por Nunes (2011, 2015), (ii) Curitiba, também já investigados por Milan (2015), e (iii) Porto Alegre, que serão aqui analisados.

\section{Estudos sobre o padrão entonacional de sentenças declarativas neutras e interrogativas totais nos falares de Florianópolis, Curitiba e Porto Alegre}

Diferentes estudos de cunho prosódico-entoacional foram desenvolvidos com foco nas três capitais do Sul do Brasil (CUNHA, 2000; MILAN, 2015; NUNES, 2015; NUNES; RILLIARD; SEARA, 2015; CASTELO; FROTA, 2016; MILAN; KLUGE, 2017a e b, dentre outros).

Nunes (2011), investigando as declarativas neutras e interrogativas totais no falar florianopolitano com base na metodologia do Projeto AMPER-POR, observou que, no pré-núcleo com oxítonas, há proeminência nas sílabas tônicas em ambas as modalidades. Nas paroxítonas, ocorre um pico no final da tônica, ou seja, alinhamento à direita e, nas proparoxítonas, para a interrogativa, há um movimento de subida de F0 também na tônica com alinhamento do pico à direita; enquanto para a declarativa, o movimento de subida de F0 ocorre na postônica.

Nunes (2015) observou, nas produções de interrogativas totais de florianopolitanos, também sob os critérios do Projeto AMPER-POR, diferenças no comportamento dessas curvas melódicas. Foi verificado que, para a região nuclear, há menor variação de F0 para o movimento de subida nas produções de blumenauenses e florianopolitanos se comparadas às produções de chapecoenses e lageanos. Então, percebemos que os dados dos florianopolitanos, quando comparados aos dos porto alegrenses, que apresentam um movimento menos acentuado, poderão exibir também uma menor variação, uma vez que o movimento de subida da curva de F0 no falar florianopolitano mostra-se bastante atenuado, como já indicado pela autora.

Milan e Kluge (2017b), estudando as produções de curitibanos sob os critérios do Projeto anteriormente referido, observaram que os pré-núcleos das declarativas neutras e das interrogativas totais exibem contornos diferentes e os valores de F0 (de uma modalidade para a outra) foram considerados significativamente distintos a partir de testes 
estatísticos. As autoras elaboraram testes de percepção que mostraram que os curitibanos identificam uma pergunta e uma afirmação apenas pelo pré-núcleo. Apontaram também que diferenças de 3 st já são percebidas pelo ouvido humano. Esse apontamento ratifica os achados de diferentes autores, como t'Hart (1981), Consoni e Ferreira Neto (2008); Martins e Ferreira Netto (2010), que também mostraram, com base em testes estatísticos, que sujeitos percebem com acuidade variações de 3 st ou mais.

Cunha (2000), investigando os falares regionais, analisou produções de porto alegrenses. Seu objetivo, no entanto, era verificar (i) marcas prosódicas que caracterizam esses falares regionais, (ii) se essas marcas eram sensíveis ao estilo de fala e (iii) se seria possível verificar a localização e a frequência dessas marcas. Seus resultados mostraram que os falantes de Porto Alegre exibem uma elevação da F0 na sílaba tônica, a qual recebe também a maior intensidade e a maior duração, diferentemente do que ocorre com dados das cidades de São Paulo, Recife, Rio de Janeiro e Salvador. Para essas cidades, foi verificada uma queda melódica entre a pré-tônica e a tônica. No entanto, esses dados foram coletados do Projeto NURC, obtidos com base na leitura interpretativa de frases curtas e soltas, de padrão assertivo ou interrogativo.

Essas observações sobre dados referentes às cidades que aqui pesquisamos mostram que podemos continuar nossa empreitada, visto que a constituição do corpus do Projeto AMPER-POR nos permitirá fazer comparações entre dados que foram coletados e analisados sob os mesmos critérios e que apresentam estrutura sintática e lexical semelhantes. Passemos então à metodologia empregada no presente estudo.

\section{Metodologia}

\section{Descrição da coleta e análise dos dados}

Os procedimentos metodológicos empregados na coleta, tratamento e análise dos dados são aqueles estabelecidos pelo Projeto AMPER-POR que possibilita a comparação entre diferentes falares e modalidades de sentenças, pois as estratégias de coleta de dados, os contextos linguísticos e as estruturas sintáticas são semelhantes para todas as línguas românicas que se integram no referido Projeto. Com essa metodologia, tem-se a gravação de sentenças declarativas neutras (não se posiciona subjetivamente quanto ao que está sendo dito, mas apenas introduz-se uma informação) e interrogativas totais (espera-se resposta sim ou não), elicitadas a partir de imagens que representam um sintagma nominal seguido do verbo "gostar" flexionado (representado por uma imagem de um coração) e de sintagmas preposicionados ou adjetivados. O número de sílabas que compõe cada sentença varia de 10 a 14. E as imagens que compõem o corpus do 
- A variação na entoação de declarativas neutras e interrogativas totais nas três capitais do Sul do Brasil

português brasileiro (PB), baseado no corpus do português europeu (PE), são referentes aos vocábulos: bisavô, nadador, Salvador; Renato, pateta, Veneza; pássaro, bêbado, Mônaco. Com esses vocábulos, todos com três sílabas, tem-se as diferentes posições acentuais do português: oxítonas, paroxítonas e proparoxítonas.

$\mathrm{Na}$ Figura 2, podem ser observados exemplos de frases montadas com as imagens estabelecidas pelo Projeto AMPER-POR. A partir dessas imagens, são produzidas as sentenças: (O) bisavô gosta de (do) Renato, nas modalidades (a) declarativa neutra e (b) interrogativa total.

Figura 2. Sentenças do corpus do Projeto AMPER-POR, representadas por imagens, correspondentes a O bisavô gosta do Renato./?, nas modalidades (a) declarativa neutra e (b) interrogativa total

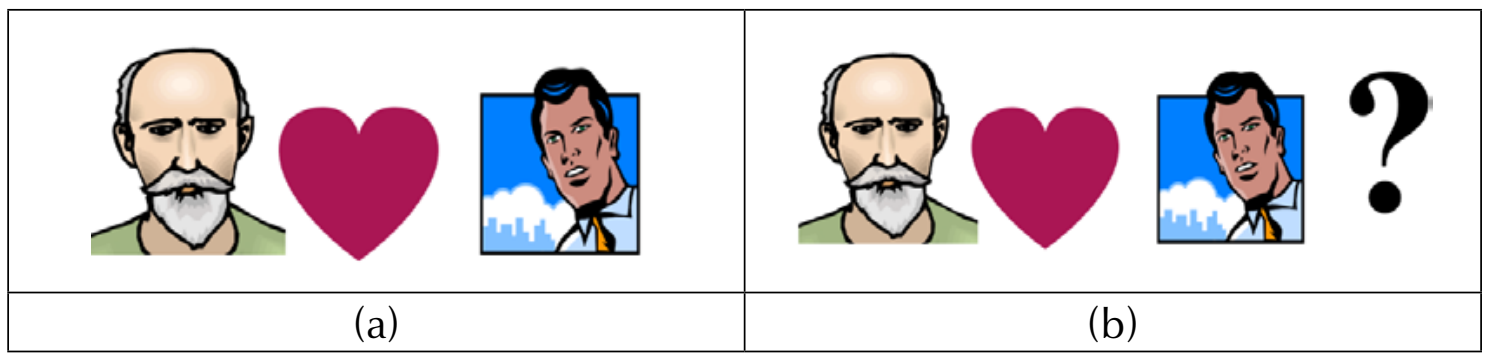

Fonte: Imagens retiradas do corpus AMPER-POR elaborado para o português do Brasil.

O corpus de base é composto por 66 sentenças (33 declarativas neutras e 33 interrogativas totais). Do material gravado, foram selecionadas três repetições e, dessa maneira, obtém-se um total de 198 sentenças (66 sentenças x 3 repetições) para cada informante.

Fazem parte do presente estudo três informantes, todos do sexo masculino, escolaridade média, idades entre 35 e 45 anos, nativos das três capitais do sul do Brasil (Porto Alegre (RS); Florianópolis (SC) e Curitiba (PR)). Como estamos iniciando as análises comparativas das três capitais, selecionamos, para este estudo, os dados referentes apenas às sentenças compostas por 10 vogais, com estrutura sintática simples, do tipo SVO. Temos assim um total de 162 sentenças (18 sentenças $\times 3$ repetições $x 3$ informantes). Veja, no Quadro 1, as sentenças-alvo. 
Quadro 1. Sentenças do corpus AMPER-POR constituídas de 10 sílabas e seus respectivos códigos AMPER

\begin{tabular}{|l|l|l|l|}
\hline \multicolumn{2}{|c|}{ Declarativa } & \multicolumn{2}{c|}{ Interrogativa } \\
\hline kwka & O bisavô gosta do bisavô. & kwki & O bisavô gosta do bisavô? \\
\hline kwpa & O bisavô gosta do pássaro. & kwpi & O bisavô gosta do pássaro? \\
\hline kwta & O bisavô gosta do Renato. & kwti & O bisavô gosta do Renato? \\
\hline pwka & O pássaro gosta do bisavô. & pwki & O pássaro gosta do bisavô? \\
\hline pwpa & O pássaro gosta do pássaro. & pwpi & O pássaro gosta do pássaro? \\
\hline pwta & O pássaro gosta do Renato. & pwti & O pássaro gosta do Renato? \\
\hline twka & O Renato gosta do bisavô. & twki & O Renato gosta do bisavô? \\
\hline twpa & O Renato gosta do pássaro. & twpi & O Renato gosta do pássaro? \\
\hline twta & O Renato gosta do Renato. & twti & O Renato gosta do Renato? \\
\hline
\end{tabular}

Fonte: Elaboração própria

A partir do Praat (BOERSMA; WEENINK, 2016), os dados foram segmentados e cada sentença teve suas vogais etiquetadas, conforme ilustra a Figura 3.

Figura 3. Exemplo de etiquetagem das sentenças do corpus do Projeto AMPER-POR. Forma de onda, espectrograma, curva de $\mathrm{F} 0$ e camada de etiquetagem da sentença O bisavô gosta do Renato?, produzida por um informante florianopolitano

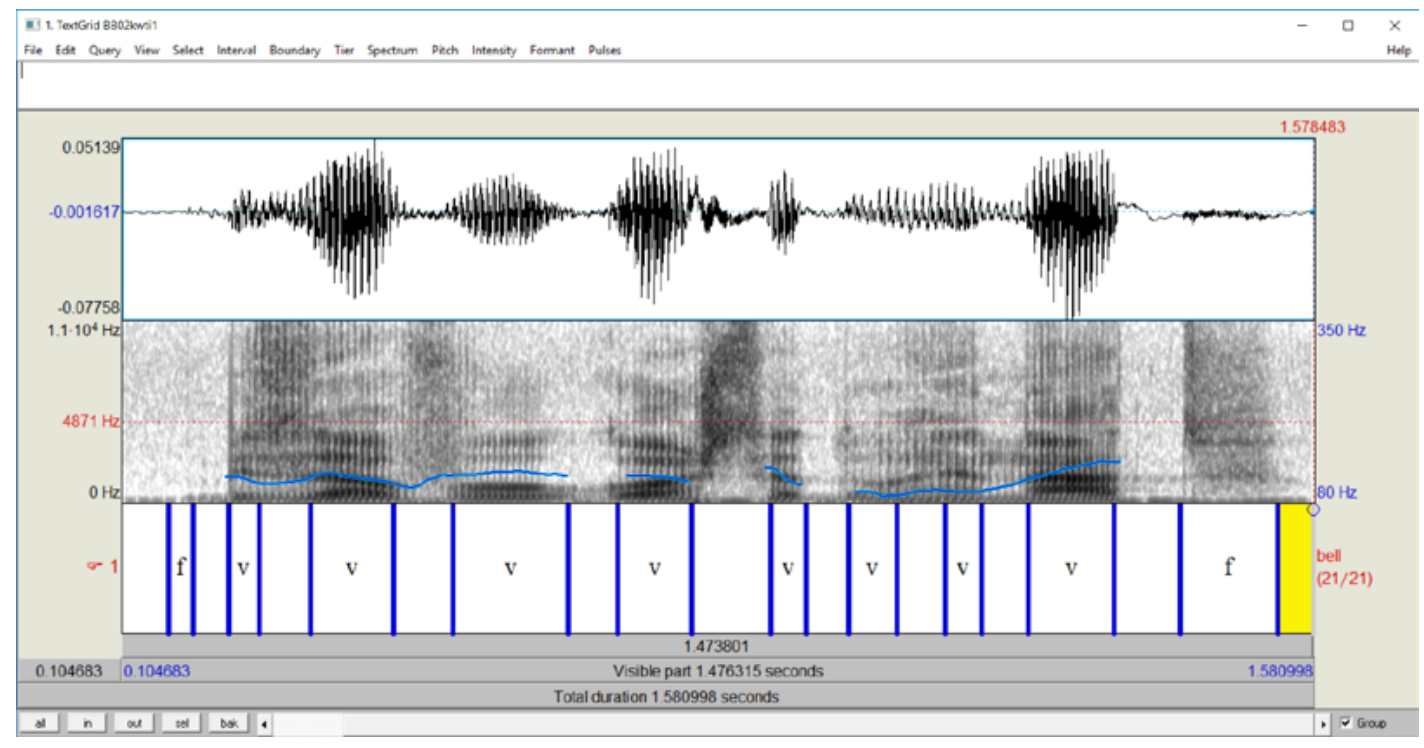

Fonte: Elaboração própria 
- A variação na entoação de declarativas neutras e interrogativas totais nas três capitais do Sul do Brasil

Em seguida, os arquivos de áudio e das etiquetagens são usados em um script ${ }^{3}$ do Praat que coleta automaticamente os valores de F0, duração e intensidade. Como se vê na Figura 4, para F0, são calculados três valores (inicial, medial e final), assim definido pelo Projeto AMPER, para melhor avaliarmos a evolução do movimento intra-silábico de cada uma das vogais analisadas. Resultados dessas coletas são exemplificados na Figura 4.

Figura 4. Tabela de valores de duração, intensidade e F0, coletados automaticamente via script do Praat, referentes à sentença: O bisavô gosta do Renato?, produzida por um informante florianopolitano ${ }^{4}$

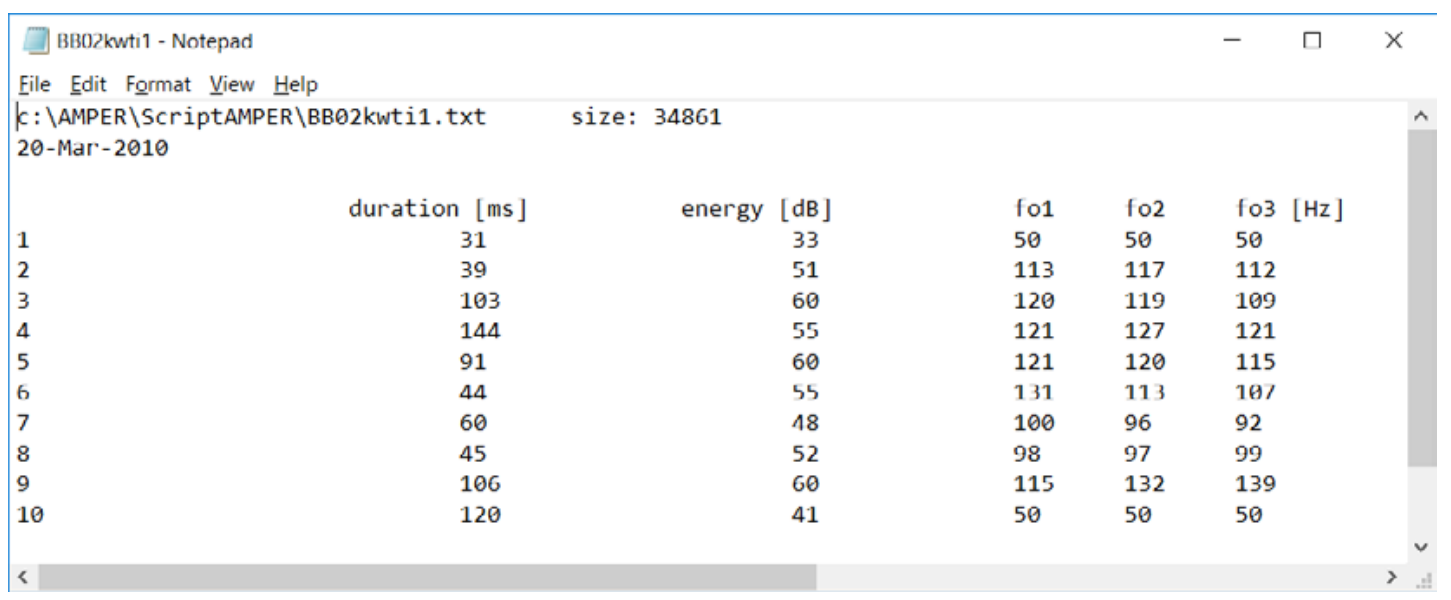

Fonte: Elaboração própria

Com esses dados, analisamos as curvas de F0, assim como comparamos os valores de F0 (normalizados em semitons) entre modalidades e entre os informantes das três capitais. Esses valores foram analisados e comparados tanto no núcleo entonacional (parte final das sentenças) quanto no pré-núcleo (parte inicial das sentenças). Foram consideradas as posições do pico de F0 em cada região, assim como o seu alinhamento (à direita, à esquerda ou medial).

Os dados inscritos nessas tabelas foram inseridos em uma interface do Matlab que disponibiliza figuras, apresentando sobreposição de curvas de F0 de interrogativas e declarativas, elaboradas a partir de médias de produção, e também histogramas dos valores de duração e de intensidade das modalidades em estudo.

3 Os scripts usados foram criados expressamente para o Projeto AMPER, por Albert Rilliard. Ver mais informações sobre instrumentos de análise em: http://www.varialing.eu/?page_id=704

4 Quando a vogal não foi produzida pelo informante, na etiquetagem, essa ausência é anotada por f, e os valores de F0 são indicados por $50 \mathrm{~Hz}$, conforme pode ser observado nas Figuras 3 e 4, respectivamente. 
Para que pudéssemos observar se as semelhanças ou diferenças que foram verificadas objetivamente para os dados acústicos das três capitais eram também percebidas pelos ouvintes, realizamos testes de percepção que serão descritos a seguir.

\section{Descrição dos testes de percepção}

Foram realizados dois testes de percepção: um de discriminação e outro de identificação. Antes do início dos testes, foi feito um treino para que os ouvintes se habituassem ao som de estímulos sintetizados. Quer dizer, estímulos acústicos em que toda a informação é retirada, restando apenas as informações referentes à melodia produzida.

No teste de discriminação, do tipo $\mathrm{AX}$, foi apresentado um par de estímulos e o ouvinte deveria indicar se os estímulos eram iguais ou diferentes (KLUGE et al., 2013), conforme pode ser visto na Figura 5.

Figura 5. Tela do teste de discriminação

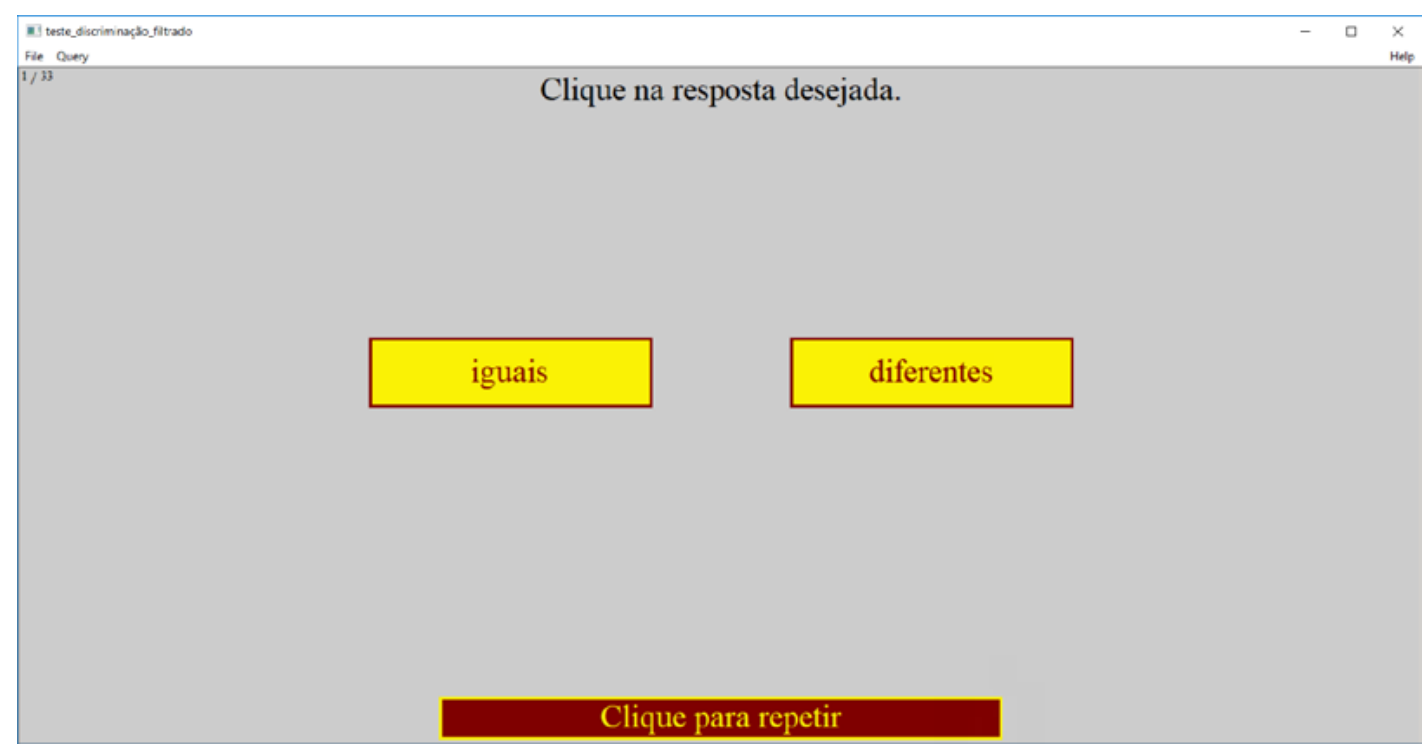

Fonte: Elaboração própria

Para a realização do teste de discriminação, o ouvinte usava um headfone, escutava o par de estímulos e poderia ouvi-los mais duas vezes, clicando em Clique para repetir. Depois disso, deveria selecionar a resposta que lhe parecesse mais adequada, decidindo se considerava os estímulos iguais ou diferentes. Foram utilizados pares com os dois estímulos iguais para os quais os ouvintes deveriam dar como resposta igual. As respostas referentes a esses pares foram usadas como critério para o descarte de ouvintes, ou seja, 
- A variação na entoação de declarativas neutras e interrogativas totais nas três capitais do Sul do Brasil

aqueles ouvintes que, nesses casos, dessem recorrentemente como resposta diferente teriam seus resultados descartados. O teste de discriminação foi montado com o objetivo de verificar se os contornos mais proeminentes das curvas de F0 na região pré-nuclear das interrogativas totais apresentados pelos curitibanos em relação aos seus contornos de declarativas eram percebidos de fato como diferentes daqueles apresentados pelos florianopolitanos e porto alegrenses. E também verificou-se se eram percebidas diferenças entre os dados produzidos por falantes de Florianópolis e Porto Alegre.

No teste de discriminação, foram criados 33 pares de estímulos sintetizados a partir da Interface do Matlab. Como dito anteriormente, nesse tipo de estímulo, ouvem-se informações somente acerca da melodia da sentença, ou seja, relacionadas aos valores de F0. Consideramos ainda na seleção dos estímulos aqueles que tinham durações semelhantes para que a duração do estímulo não fosse utilizada na percepção de diferenças, mas apenas a melodia ouvida. Nas Figuras 6(a) e 6(b), que se reproduzem abaixo, podem ser visualizadas as curvas de FO de interrogativas totais e declarativas neutras de um dos pares selecionado como estímulo.

Figura 6. Pares de estímulos empregados na comparação apresentada no teste de discriminação: (a) estímulos da região pré-nuclear da interrogativa total: O bisavô gosta do Renato?, produzida por informantes de Porto Alegre e Curitiba; (b) estímulos da região pré-nuclear da interrogativa total: $\boldsymbol{O}$ Renato gosta do pássaro?, produzida por informantes de Porto Alegre e Florianópolis

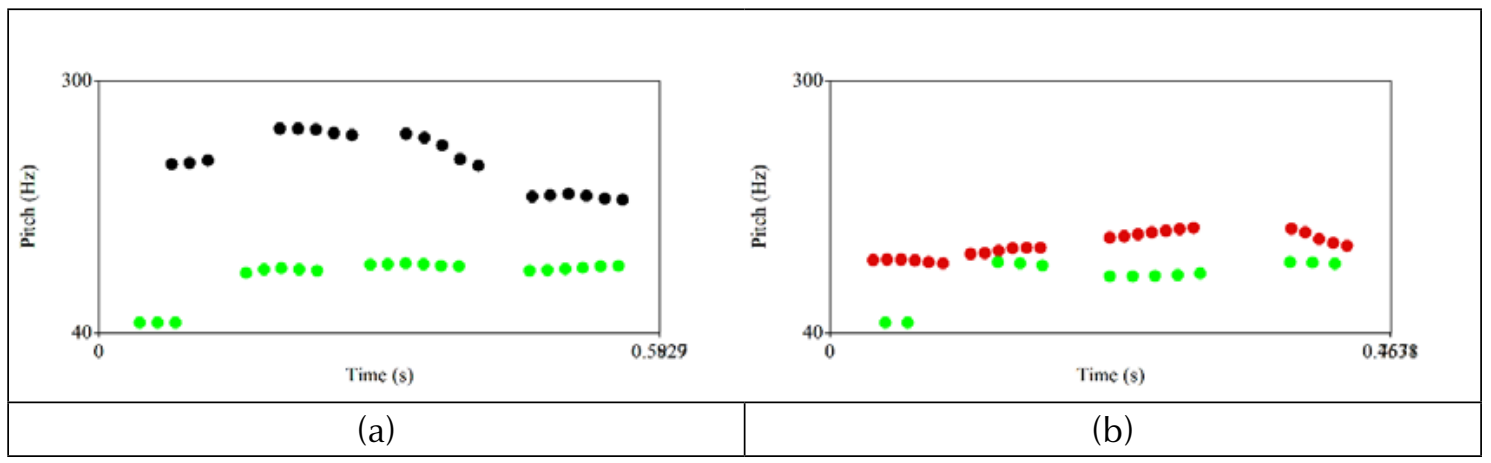

Fonte: Elaboração própria

Foi elaborado também um teste de identificação, cujos estímulos eram a região prénuclear e a região nuclear das sentenças. Foram então criados 26 estímulos sintetizados a partir da Interface do Matlab. O objetivo desse teste era observar se, apenas pela audição da região pré-nuclear, seria possível identificar as sentenças interrogativas totais ou se essa identificação ocorreria somente (ou em sua grande maioria) com a audição da região nuclear das sentenças. Para isso, os ouvintes deveriam indicar se o estímulo ouvido era 
uma afirmação, uma pergunta ou se não sabia identificar. Observe a tela do teste de identificação apresentada na Figura 7.

Figura 7. Tela do teste de identificação

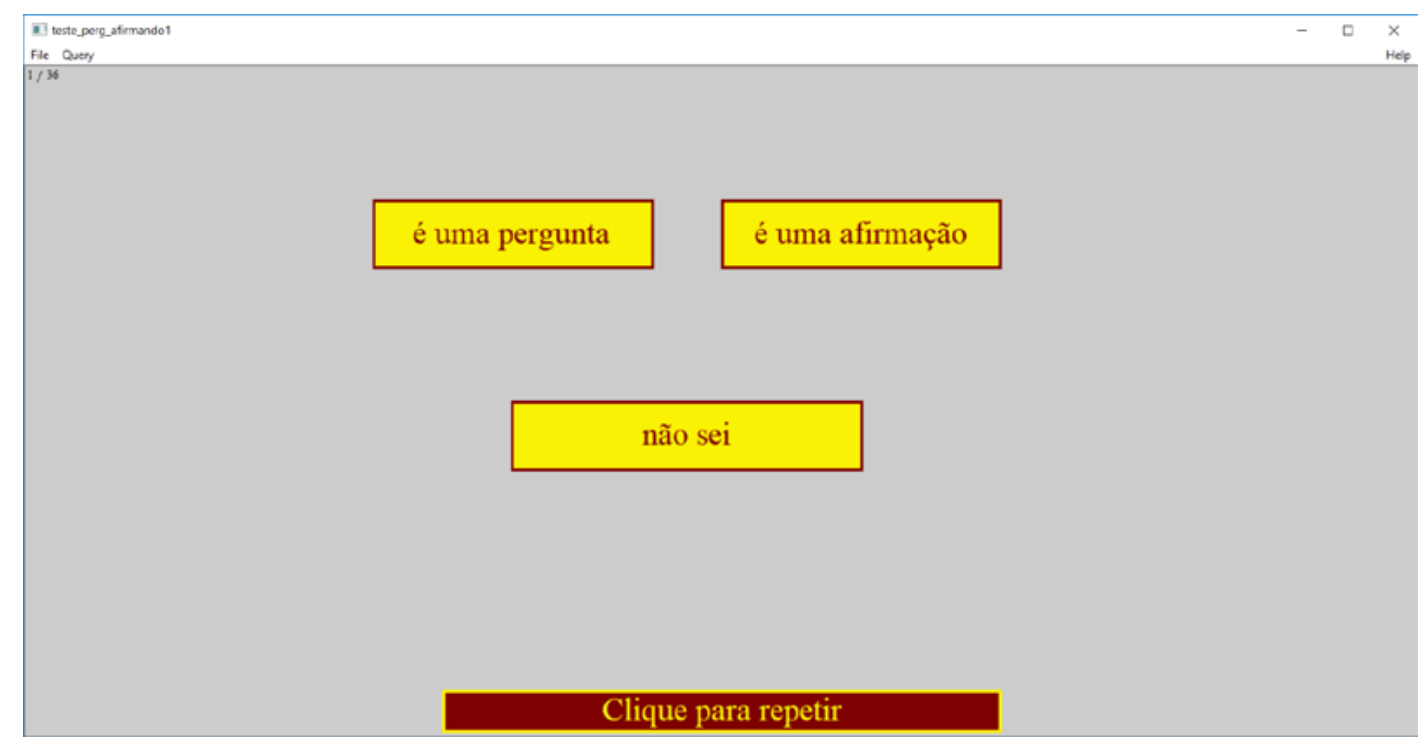

Fonte: Elaboração própria

Nos testes de identificação, tal como para os de discriminação, também era possível, antes de dar a resposta, ouvir o estímulo mais duas vezes. Nesses testes, os estímulos ouvidos também eram sínteses das sentenças produzidas. Veja, na Figura 8, estímulos das regiões pré-nuclear e nuclear que foram utilizados nos testes de identificação. 
- A variação na entoação de declarativas neutras e interrogativas totais nas três capitais do Sul do Brasil

Figura 8. Exemplos de estímulos empregados no teste de identificação: (a) estímulo referente à região pré-nuclear da sentença interrogativa total: $\boldsymbol{O}$ bisavô gosta do bisavô?, produzida pelo informante de Curitiba; (b) estímulo referente à região nuclear da sentença interrogativa total: O bisavô gosta do bisavố?, produzida pelo informante de Curitiba; (c) estímulo referente à região nuclear da sentença declarativa neutra: O pássaro gosta do bisavô., produzida pelo informante de Florianópolis; (d) estímulo referente à região nuclear da sentença interrogativa total: O pássaro gosta do bisavố?, produzida pelo informante de Florianópolis

(a) Interrogativa - Região pré-nuclear - Curitiba (PR)

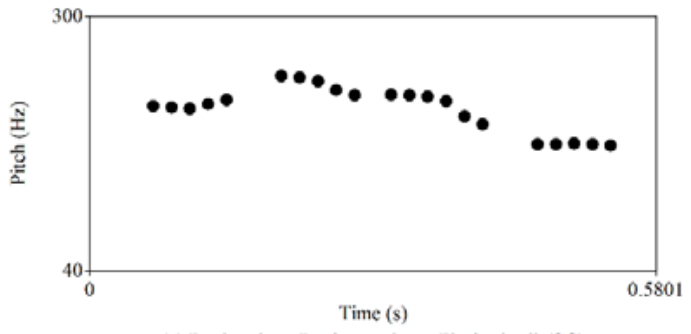

(c) Declarativa - Região nuclear - Florianópolis(SC)

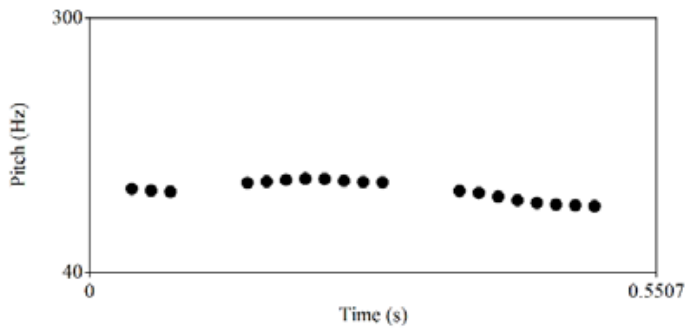

(b) Interrogativa - Região nuclear - Curitiba(PR)

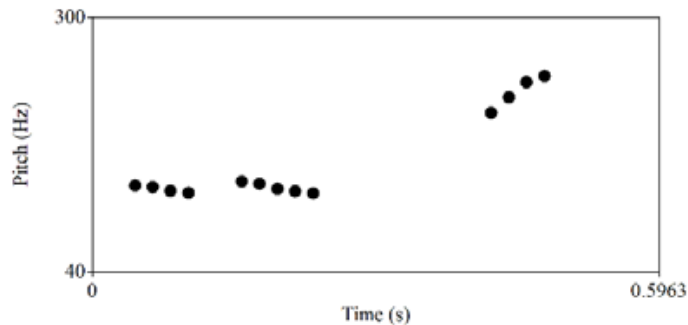

(d) Interrogativa - Região nuclear - Florianópolis(SC)

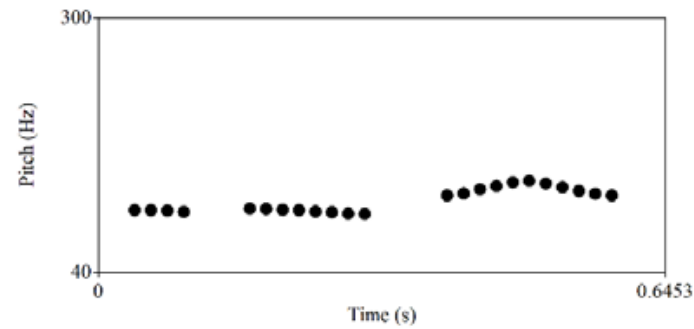

Fonte: Elaboração própria

Com os resultados dos testes de identificação, pode-se também ratificar as diferenças observadas no teste de discriminação e nos resultados objetivos.

Os testes de percepção foram aplicados a 12 ouvintes brasileiros. Como este estudo configura-se em um estudo piloto, ainda não conseguimos controlar as variedades dos ouvintes e, pelo critério de descarte descrito anteriormente, tivemos de desconsiderar as respostas de um ouvinte do Paraná. Assim, restaram 11 ouvintes que se distribuem conforme a Tabela 1. 
Tabela 1. Distribuição das características sociais dos ouvintes brasileiros que participaram dos testes de percepção ${ }^{5}$

\begin{tabular}{l|l|l|l|l|l|l|l|l}
\hline \multicolumn{2}{l|}{ Idade } & \multicolumn{4}{l|l}{ Escolaridade } & \multicolumn{2}{l}{ Localidade } \\
\hline $18-24$ & $25-52$ & graduando & graduado & $\begin{array}{l}\text { pós- } \\
\text { graduando }\end{array}$ & $\begin{array}{l}\text { pós- } \\
\text { graduado }\end{array}$ & Florianópolis & $\begin{array}{l}\text { Porto } \\
\text { Alegre }\end{array}$ & Curitiba \\
\hline 04 & 07 & 07 & 01 & 02 & 01 & 04 & 02 & 00 \\
\hline Cursos & Conhecimento de Fonética & não & pouco & & Outras localidades \\
\hline Letras & Linguística & sim & Santa Catarina & $\begin{array}{l}\text { Rio Grande do } \\
\text { Sul }\end{array}$ \\
\hline 08 & 03 & 03 & 02 & 06 & 04 & 01 \\
\hline
\end{tabular}

Fonte: Elaboração própria

Passemos então aos resultados deste estudo, apresentando primeiramente os experimentos de produção e em seguida os de percepção.

\section{Resultados}

Conforme foi estabelecido, para este estudo, iniciamos a descrição dos resultados pela observação dos movimentos de F0 relativos à sílaba em que se encontra o pico de F0, ao alinhamento do pico na sílaba e às diferenças encontradas entre declarativas e interrogativas aqui analisadas. Todos os valores de FO foram normalizados em semitons (st).

\section{Os experimentos de produção}

Os dados mostrados na Tabela 2 foram descritos com base no comportamento mais frequente dos parâmetros analisados.

5 Informamos que as características sociais apresentadas nesta tabela não puderam, neste primeiro momento, ser controladas. No entanto, acreditamos que as respostas dos testes relacionados ao conhecimento da área de Fonética e às áreas afins possam ter resultados diferentes quando não há o conhecimento da área e os cursos não são de áreas afins. Idade, escolaridade e localidade também podem condicionar as respostas aos testes. Daí a razão de detalhar tais características para o grupo de ouvintes dos testes realizados. Certamente também as levaremos em consideração nos próximos estudos perceptuais, aumentando assim o número de ouvintes. 
- A variação na entoação de declarativas neutras e interrogativas totais nas três capitais do Sul do Brasil

Tabela 2. Observações relativas à sílaba em que se encontra o pico de F0 e ao alinhamento do pico de F0 na sílaba para a região pré-nuclear concernentes às três capitais do Sul do Brasil

\begin{tabular}{|c|c|c|c|c|}
\hline \multirow{2}{*}{ Localidades } & \multicolumn{2}{|c|}{ Sílaba em que se encontra o pico de F0 } & \multicolumn{2}{|c|}{ Alinhamento do pico de FO na sílaba } \\
\hline & Decl. & Inter. & Decl. & Inter. \\
\hline \multicolumn{5}{|c|}{ Oxítonas } \\
\hline Curitiba (PR) & pretônical & tônica & medial/à esquerda & à direita \\
\hline Florianópolis (SC) & tônica & tônica & medial & medial \\
\hline Porto Alegre (RS) & pretônica $1 /$ tônica & tônica & medial & à direita \\
\hline \multicolumn{5}{|c|}{ Paroxítonas } \\
\hline Curitiba (PR) & postônica & pretônica & à esquerda/medial & medial \\
\hline Florianópolis (SC) & tônica & tônica & à direita & à direita \\
\hline Porto Alegre (RS) & postônica & postônica & à esquerda/medial & $\begin{array}{l}\text { à esquerda/ } \\
\text { medial }\end{array}$ \\
\hline \multicolumn{5}{|c|}{ Proparoxítonas } \\
\hline Curitiba (PR) & postônica2 & tônica & à direita/medial & à esquerda \\
\hline Florianópolis (SC) & postônical & postônical & à esquerda & à esquerda \\
\hline Porto Alegre (RS) & postônical & postônical & à esquerda & $\begin{array}{l}\text { à esquerda/ } \\
\text { medial }\end{array}$ \\
\hline
\end{tabular}

Fonte: Elaboração própria

A observação da localização do pico de F0 na região pré-nuclear, resumida na Tabela 2, mostra que existem maiores semelhanças entre as produções de Florianópolis e Porto Alegre, principalmente quando o pré-núcleo é constituído de vocábulos proparoxítonos. De forma geral, quando consideramos a sílaba em que se encontra o pico de F0 e seu alinhamento na sílaba, vemos, pela Tabela 2, que há semelhanças de comportamento entre Curitiba e Porto Alegre (em cinza claro); entre Porto Alegre e Florianópolis (em cinza escuro); ou ainda entre as três capitais (em rosa claro). Não houve comportamento semelhante, no entanto, entre Curitiba e Florianópolis. Quando havia semelhança entre os dados dessas duas cidades, elas se assemelhavam também ao comportamento dos dados produzidos pelos falantes de Porto Alegre (veja em rosa claro na Tabela 2).

Os resultados reportados por Nunes (2011, 2015) e Milan (2015), referentes aos dados de Florianópolis e Curitiba, respectivamente, sendo os mesmos analisados por nós, vêm ao encontro dos nossos resultados, corroborando-os. Vejamos esses resultados que, relembrando, no presente estudo, são referentes apenas às sentenças com 10 vogais. Nas declarativas com pré-núcleo oxítono, os dados de Florianópolis exibiram o pico das curvas de F0 sempre nas sílabas tônicas. Com vocábulos paroxítonos, o florianopolitano, em ambas as modalidades, produziu sentenças com picos de F0 na tônica e com alinhamento à direita. Com vocábulos proparoxítonos, os picos das curvas de F0, nas 
declarativas e interrogativas, de modo geral, estão na pós-tônica 1 (aquela que segue imediatamente a tônica). O alinhamento nos pré-núcleos com proparoxítonas ocorre à esquerda da postônica 1.

Para os curitibanos, observa-se, nos pré-núcleos com vocábulos oxítonos, que o pico de F0 se encontra na pretônica 1 (primeira sílaba da palavra) para as declarativas com alinhamento medial ou à esquerda e, nas interrogativas, o pico está à direita na tônica. Para os pré-núcleos com paroxítonas, o pico de F0 encontra-se, para as declarativas, à esquerda na postônica ou no seu centro e, nas interrogativas, no centro da pretônica. Para os pré-núcleos com proparoxítonas, verifica-se, para a modalidade declarativa, um pico de F0 à direita ou no centro da postônica 2 e, para a interrogativa, o pico localiza-se à esquerda na tônica.

Para os porto alegrenses, nos pré-núcleos com vocábulos oxítonos, foi verificado, para as declarativas, o pico de F0 na pretônical ou na tônica e, para as interrogativas, o pico na tônica, com alinhamento medial ou à direita, respectivamente. Nas demais produções com vocábulos paroxítonos e proparoxítonos (para declarativas ou interrogativas), foi observado que o pico de F0 estava localizado à esquerda ou no centro da postônica 1. Esse comportamento nas paroxítonas e proparoxítonas se assemelhou ao comportamento dos pré-núcleos com paroxítonas produzidos por curitibanos e ao comportamento dos prénúcleos com proparoxítonas produzidos por florianopolitanos.

Todavia, quando nos atemos aos valores de diferenças de F0 (em st) entre declarativas e interrogativas, expostos na Tabela 3, as produções de Curitiba se afastam bastante do que ocorre com as produções de Florianópolis e Porto Alegre, apresentando, para os curitibanos, os valores mais altos de diferenças que são sempre bastante superiores a 3 st. Entre as regiões pré-nucleares de produções de Florianópolis e Porto Alegre, de maneira geral, os valores de diferenças não ultrapassam ou ficam muito próximos dos 3 st. 
- A variação na entoação de declarativas neutras e interrogativas totais nas três capitais do Sul do Brasil

Tabela 3. Valores médios de diferenças entre o F0 (em st), coletados em 3 pontos de cada sílaba que compõe os vocábulos do pré-núcleo de declarativas neutras e interrogativas totais nas três capitais estudadas

\begin{tabular}{|c|c|c|c|c|c|c|c|c|c|}
\hline Localidades & \multicolumn{9}{|c|}{ Oxítonas } \\
\hline Curitiba (PR) & 5.37 & 5.32 & 6.64 & 7.77 & 7.51 & 7.13 & 8.17 & 8.66 & 6.86 \\
\hline Florianópolis (SC) & 1.01 & 1.42 & 1.85 & 0.98 & 0.98 & 0.96 & 1.48 & 1.62 & 1.03 \\
\hline Porto Alegre (RS) & 0.99 & 0.71 & 0.91 & 1.45 & 1.66 & 1.98 & 1.33 & 1.63 & 1.88 \\
\hline \multicolumn{10}{|c|}{ Paroxítonas } \\
\hline Curitiba (PR) & 5.21 & 5.95 & 6.40 & 6.24 & 5.67 & 5.58 & 3.16 & 3.73 & 4.07 \\
\hline Florianópolis (SC) & 0.66 & 0.86 & 0.97 & 1.75 & 2.18 & 1.72 & 1.36 & 0.91 & 1.04 \\
\hline Porto Alegre (RS) & 1.24 & 0.62 & 0.61 & 1.36 & 0.71 & 1.17 & 2.30 & 2.56 & 2.14 \\
\hline \multicolumn{10}{|c|}{ Proparoxítonas } \\
\hline Curitiba (PR) & 9.97 & 11.31 & 11.70 & 6.78 & 6.69 & 5.59 & 3.14 & 2.29 & 2.53 \\
\hline Florianópolis (SC) & 2.27 & 1.82 & 1.93 & 2.40 & 2.25 & 2.60 & 2.13 & 1.77 & 1.81 \\
\hline Porto Alegre (RS) & 2.02 & 0.87 & 0.85 & 3.76 & 3.73 & 3.55 & 2.96 & 3.12 & 2.88 \\
\hline
\end{tabular}

Fonte: Elaboração própria

Analisando mais detalhadamente, esses resultados indicam que, para os curitibanos, nas palavras oxítonas, paroxítonas e nas duas primeiras sílabas das proparoxítonas, os valores são muito superiores aos 3 st, que são considerados suficientes para a percepção de diferenças. Esses dados vão ao encontro dos achados de Milan e Kluge (2017a) quanto à observação de diferenças estatisticamente relevantes na região pré-nuclear de declarativas e interrogativas para falantes de Curitiba. Os resultados mostrados na Tabela 4 evidenciam as diferenças entre Curitiba e as duas outras capitais, mas também salientam semelhanças de comportamento entre as produções de florianopolitanos e porto alegrenses.

Os resultados resumidos na Tabela 3, referentes à região pré-nuclear entre interrogativas e declarativas, nos levam a dizer que não seriam percebidas diferenças entre estímulos de florianopolitanos e porto-alegrenses, já que os valores mais altos de diferenças não são superiores a 3 st. No entanto, se compararmos essas mesmas regiões de interrogativas e declarativas, produzidas por curitibanos, tais diferenças seriam percebidas. Os resultados dos testes perceptuais poderão ratificar ou não esses apontamentos. Passemos agora à análise da região nuclear.

Pela Tabela 4, podemos verificar os resultados referentes ao núcleo entoacional, levando-se em conta a sílaba em que se encontra o pico de F0 e seu alinhamento. Em relação a esses parâmetros, apontamos novamente uma maior semelhança entre as 
produções de florianopolitanos e porto alegrenses. Nesses casos, para as oxítonas e paroxítonas das declarativas neutras de florianopolitanos e porto alegrenses, o pico de F0 se encontra nas pretônicas com alinhamento medial, em conformidade com as análises de Nunes (2011). Entretanto, nas proparoxítonas, o pico ocorre na tônica e tem alinhamento à esquerda ou adiantado, como também indica Nunes (2011).

Tabela 4. Observações relativas à sílaba em que se encontra o pico de F0 e ao alinhamento do pico de F0 na sílaba para a região nuclear concernentes às três capitais do Sul do Brasil

\begin{tabular}{|c|c|c|c|c|}
\hline \multirow{2}{*}{ Localidades } & \multicolumn{2}{|c|}{ Sílaba em que se encontra o pico de F0 } & \multicolumn{2}{|c|}{ Alinhamento do pico de F0 na sílaba } \\
\hline & Decl. & Inter. & Decl. & Inter. \\
\hline \multicolumn{5}{|c|}{ Oxítonas } \\
\hline Curitiba (PR) & ton & ton & à esquerda & à direita \\
\hline Florianópolis (SC) & pret2 & ton & medial & medial \\
\hline Porto Alegre (RS) & pret2 & ton & medial/à esquerda & à direita \\
\hline \multicolumn{5}{|c|}{ Paroxítonas } \\
\hline Curitiba (PR) & ton & ton & à esquerda & à direita \\
\hline Florianópolis (SC) & pret1 & ton & medial & à direita \\
\hline Porto Alegre (RS) & pret1 & ton & medial & à direita \\
\hline \multicolumn{5}{|c|}{ Proparoxítonas } \\
\hline Curitiba (PR) & ton & post1 & à esquerda & à esquerda \\
\hline Florianópolis (SC) & ton & ton & à esquerda & à direita/medial \\
\hline Porto Alegre (RS) & ton & post1 & à esquerda & à esquerda \\
\hline
\end{tabular}

Fonte: Elaboração própria

Ainda pela Tabela 4, observa-se, para as interrogativas produzidas por florianopolitanos, que, no núcleo formado por oxítonas e paroxítonas, o pico de F0 também se encontra, predominantemente, na sílaba tônica, com alinhamento à direita, ou seja, no final da tônica, conforme constatado por Nunes (2015) e Moraes (2008), ou no centro da sílaba. No núcleo de sentenças interrogativas, composto por vocábulos proparoxítonos, o comportamento é o já apresentado em Nunes (2015), ou seja, movimento ascendente descendente (medial) na tônica ou à direita na tônica.

Para os porto alegrenses, nos núcleos formados por vocábulos oxítonos, é observado o pico de F0 à esquerda da tônica, ou seja, apresenta-se no limite entre a pretônica2 e a tônica, exibindo, assim, um movimento de descida na tônica, conforme salientado por Milan (2015), para a variedade dialetal de Curitiba. Ainda com base na localização do pico na sílaba e seu alinhamento, verificamos, nas produções interrogativas de porto alegrenses, que os dados também se assemelham aos de curitibanos. Nos núcleos com palavras oxítonas e paroxítonas, o pico de F0 apresenta-se à direita na tônica. Já nos núcleos com proparoxítonas, o pico ocorre à esquerda na postônica1. 
- A variação na entoação de declarativas neutras e interrogativas totais nas três capitais do Sul do Brasil

Analisemos agora a Tabela 5 que mostra os valores médios de diferenças de F0 (em st) entre declarativas neutras e interrogativas totais no núcleo entonacional.

Tabela 5. Diferenças médias entre o núcleo das declarativas e interrogativas nas três capitais estudadas

\begin{tabular}{|c|c|c|c|c|c|c|c|c|c|}
\hline Localidades & \multicolumn{9}{|c|}{ Oxítonas } \\
\hline Curitiba (PR) & 5.15 & 6.81 & 6.83 & 8.92 & 11.08 & 10.30 & 9.64 & 2.35 & 7.63 \\
\hline Florianópolis (SC) & 1.85 & 1.90 & 2.58 & 4.21 & 4.80 & 4.93 & 1.55 & 3.54 & 2.82 \\
\hline Porto Alegre (RS) & 0.74 & 0.58 & 0.44 & 1.37 & 1.77 & 1.64 & 0.71 & 3.05 & 5.54 \\
\hline \multicolumn{10}{|c|}{ Paroxítonas } \\
\hline Curitiba (PR) & 4.38 & 5.01 & 5.20 & 9.91 & 4.22 & 5.57 & 0.00 & 0.00 & 0.00 \\
\hline Florianópolis (SC) & 4.61 & 5.49 & 5.29 & 2.81 & 3.30 & 6.37 & 0.00 & 0.00 & 0.00 \\
\hline Porto Alegre (RS) & 1.18 & 2.82 & 2.99 & 0.84 & 1.42 & 5.36 & 0.00 & 0.00 & 0.00 \\
\hline \multicolumn{10}{|c|}{ Proparoxítonas } \\
\hline Curitiba (PR) & 9.30 & 6.68 & 3.97 & 0.00 & 0.00 & 0.00 & 0.00 & 0.00 & 0.00 \\
\hline Florianópolis (SC) & 2.03 & 1.97 & 3.69 & 0.65 & 0.52 & 0.43 & 0.00 & 0.00 & 0.00 \\
\hline Porto Alegre (RS) & 2.84 & 1.40 & 3.35 & 0.92 & 0.87 & 0.76 & 2.00 & 1.35 & 1.13 \\
\hline
\end{tabular}

Fonte: Elaboração própria

Na Tabela 5, vemos que há sílabas dessas sentenças em que são observadas diferenças de F0 superiores a 3 st. Para os curitibanos, o número de sílabas com diferenças superiores a 3 st é bem superior aos dois outros falares. As diferenças menos evidentes são referentes, principalmente, aos dados dos porto alegrenses. Esse comportamento é atestado pelos gráficos apresentados na Figura 9 que evidenciam a variação no conjunto de valores de $\mathrm{F}^{+}$referentes ao núcleo entonacional formado por paroxítonas para os três falares. Essa variação é semelhante para vocábulos oxítonos e proparoxítonos.

Pelos gráficos mostrados na Figura 9, novamente, percebe-se um comportamento distinto entre curitibanos, de um lado, e florianopolitanos e porto alegrenses, de outro. Salienta-se também a pouca variação dos valores encontrada especialmente nos dados de porto alegrenses. Esse fato também pode ser visto na Figura 10. 
Figura 9. Variação no conjunto de valores de F0 (em st) na região nuclear formada por paroxítonas de declarativas neutras (A) e interrogativas totais (I), produzidas por (a) curitibanos,

(b) florianopolitanos e (c) porto alegrenses

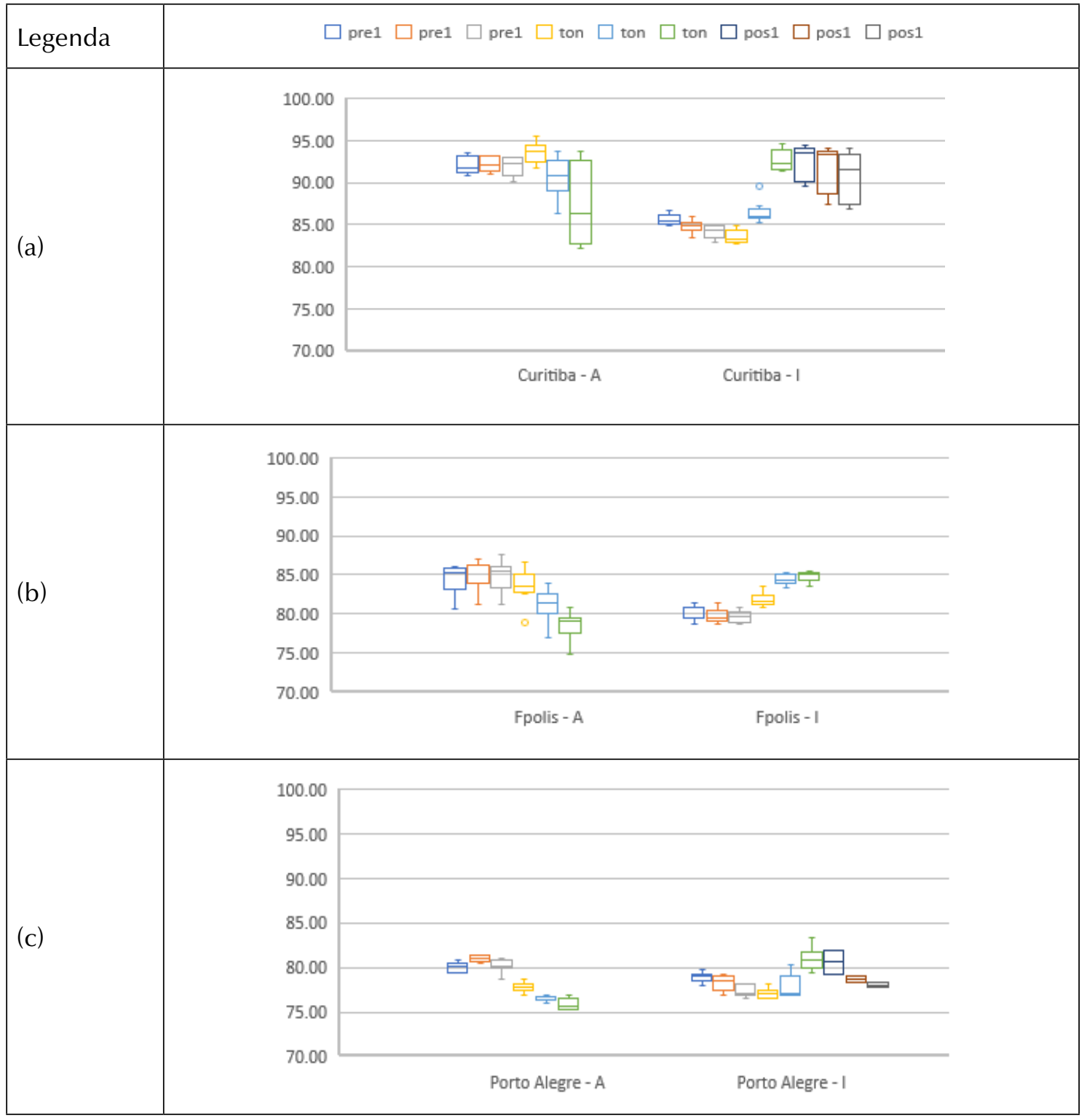

Fonte: Elaboração própria

Na Figura 10, é mostrada a curva média de F0 de declarativas neutras e interrogativas totais e observa-se a similaridade dos contornos declarativos e interrogativos entre as produções de Florianópolis e Porto Alegre e as diferenças entre esses dois contornos referentes às produções de Curitiba. 
- A variação na entoação de declarativas neutras e interrogativas totais nas três capitais do Sul do Brasil

Figura 10. Curva de F0 (st) das sentenças declarativas (em vermelho) e interrogativas (em azul): "O bisavô gosta do bisavô", codificadas como kwk; "O bisavô gosta do pássaro", codificadas como kwp; "O bisavô gosta do Renato", codificadas como kwt; produzidas pelos informantes masculinos das três capitais brasileiras (Porto Alegre, Florianópolis e Curitiba)

\begin{tabular}{|c|c|c|}
\hline Porto Alegre & Florianópolis & Curitiba \\
\hline 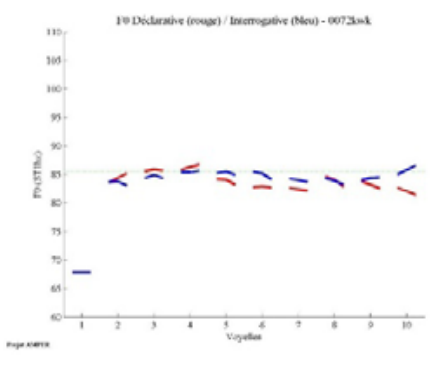 & 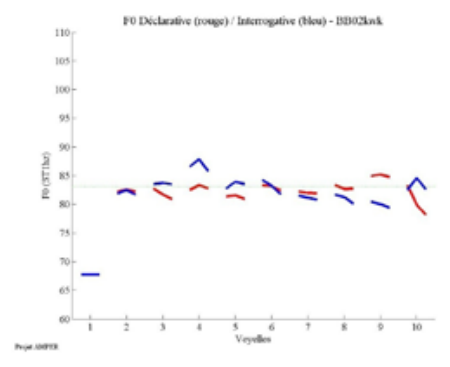 & 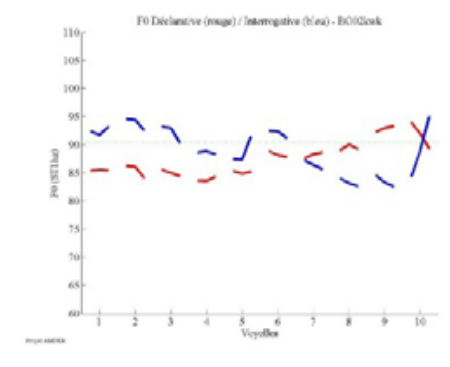 \\
\hline 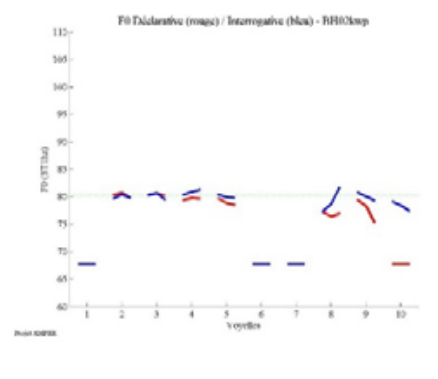 & (10) & 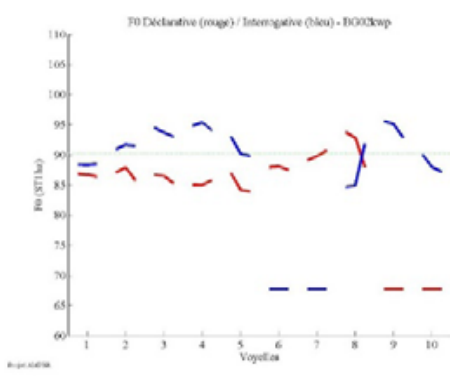 \\
\hline 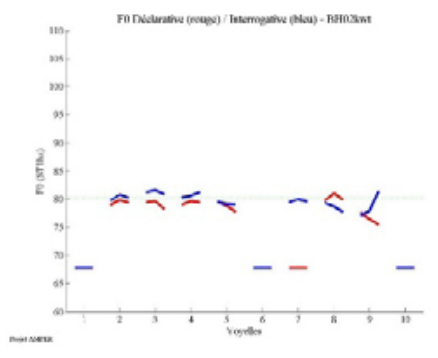 & 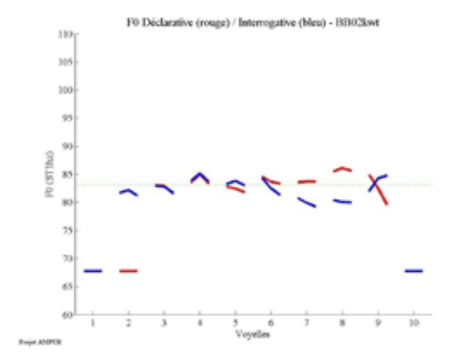 & - \\
\hline
\end{tabular}

Fonte: Elaboração própria

Apresentados os resultados dos experimentos de produção, passemos à descrição dos resultados obtidos nos experimentos de percepção.

\section{Os experimentos de percepção}

O primeiro teste de percepção realizado com 12 ouvintes foi o de discriminação que avaliava se ouvintes de diferentes regiões do Sul do Brasil percebiam diferenças entre declarativas neutras e interrogativas totais, produzidas por curitibanos, florianopolitanos e porto alegrenses. Não conseguimos montar ainda um grupo de ouvintes com um número suficiente de sujeitos das cidades aqui estudadas. Esse primeiro teste serviu apenas como 
um piloto para os estudos que ainda se seguirão. No teste de discriminação, comparamos apenas os pré-núcleos entoacionais das sentenças, uma vez que percebemos, pelas análises objetivas, que diferenças, quanto aos valores de F0, foram verificadas entre o grupo de curitibanos e os dois outros falares.

Apresentamos inicialmente os resultados concernentes aos pares constituídos dos mesmos estímulos e que serviram para o critério de descarte de ouvintes. Para esses estímulos, as respostas dos ouvintes deveriam ser de 100\% para igual. Na Tabela 6, são mostrados os percentuais de respostas dos ouvintes a esses pares de estímulos.

Tabela 6. Resultados do teste de discriminação com pares de estímulos iguais referentes à Curitiba, Florianópolis (Fpolis) e Porto Alegre (POA)

\begin{tabular}{l|l|l|l|l|l|l|l|l}
\hline \multirow{2}{*}{ Estímulos } & \multicolumn{2}{l|l|l|l|l}{ Florianópolis } & \multicolumn{2}{l|}{ Porto Alegre } & \multicolumn{2}{l}{ SC } \\
\cline { 2 - 11 } & $=$ & $\neq$ & $=$ & $\neq$ & $=$ & $\neq$ & $=$ & $\neq$ \\
\hline Curitiba - Ox - Int $x$ Curitiba - Ox - Int & $100 \%$ & $0 \%$ & $100 \%$ & $0 \%$ & $100 \%$ & $0 \%$ & $100 \%$ & $0 \%$ \\
\hline Curitiba - Pro - Int $x$ Curitiba - Pro - Int & $100 \%$ & $0 \%$ & $100 \%$ & $0 \%$ & $75 \%$ & $25 \%$ & $100 \%$ & $0 \%$ \\
\hline Curitiba - Par - Int $x$ Curitiba - Par - Int & $100 \%$ & $0 \%$ & $100 \%$ & $0 \%$ & $100 \%$ & $0 \%$ & $100 \%$ & $0 \%$ \\
\hline Fpolis - Par - Decl $x$ Fpolis - Par - Decl & $75 \%$ & $25 \%$ & $100 \%$ & $0 \%$ & $75 \%$ & $25 \%$ & $100 \%$ & $0 \%$ \\
\hline POA - Par - Decl $x$ POA - Par - Decl & $100 \%$ & $0 \%$ & $100 \%$ & $0 \%$ & $100 \%$ & $0 \%$ & $100 \%$ & $0 \%$ \\
\hline
\end{tabular}

Fonte: Elaboração própria

Os resultados da Tabela 6 nos levaram ao descarte de um dos ouvintes do teste de discriminação. Vamos então aos resultados obtidos neste primeiro teste, considerando as respostas dos 11 ouvintes validados.

Comoteste de discriminação, era esperado que, quando dados deflorianopolitanos e porto alegrenses fossem comparados com os dos curitibanos (Tabela 7), os ouvintes percebessem como diferentes e, quando dados de interrogativas e declarativas de florianopolitanos fossem comparados entre si ou com sentenças de porto alegrenses (Tabela 8), que diferenças não fossem percebidas, assim como entre interrogativas e declarativas de porto alegrenses.

6 Os resultados referentes ao Rio Grande do Sul são relativos a um único informante, dessa forma, esses resultados devem ser considerados com cautela. No entanto, a percentagem de acertos dá-nos indicação de alguma consistência nas respostas dadas. 
- A variação na entoação de declarativas neutras e interrogativas totais nas três capitais do Sul do Brasil

Tabela 7. Resultados do teste de discriminação com estímulos referentes ao pré-núcleo entoacional, confrontando dados de Curitiba de um lado e Florianópolis (Fpolis) ou Porto Alegre (POA) de outro

\begin{tabular}{l|l|l}
\hline Estímulos & Igual & Diferente \\
\hline Curitiba - Ox - Int $x$ Fpolis - Ox - Int & $0 \%$ & $100 \%$ \\
\hline Curitiba - Ox - Int $x$ Curitiba - Ox - Decl & $23 \%$ & $77 \%$ \\
\hline Curitiba - Ox - Decl $x$ Fpolis - Ox - Decl & $8 \%$ & $92 \%$ \\
\hline Curitiba - Ox - Decl $x$ POA - Ox - Decl & $23 \%$ & $77 \%$ \\
\hline Curitiba - Ox - Int $x$ Fpolis - Ox - Int & $8 \%$ & $92 \%$ \\
\hline Curitiba - Ox - Int $x$ POA - Ox - Int & $15 \%$ & $85 \%$ \\
\hline POA - Ox - Int $x$ Curitiba - Ox - Int & $8 \%$ & $92 \%$ \\
\hline Curitiba - Pro - Int $x$ POA - Pro - Int & $0 \%$ & $100 \%$ \\
\hline Curitiba - Pro - Int $x$ Fpolis - Pro - Int & $15 \%$ & $85 \%$ \\
\hline
\end{tabular}

Fonte: Elaboração própria

As produções de curitibanos comparadas às produções de florianopolitanos e porto alegrenses (Tabela 7) foram consideradas sempre diferentes com percentuais que variaram de $77 \%$ a 100\%. Esses resultados confirmam os obtidos para as análises acústicas apresentadas na seção de resultados dos experimentos de produção e os achados de Milan e Kluge (2017) que comparavam apenas dados de curitibanos tendo como ouvintes também curitibanos. Em nossas análises, os resultados apresentavam diferenças entre os valores de F0 que eram bem superiores a $3 \mathrm{st}$, limite acima do qual seriam percebidas diferenças, além de outras relacionadas ao alinhamento do pico de F0 e à sílaba em que se encontrava o pico de F0. Lembramos que esse primeiro teste avaliava apenas diferenças percebidas na região pré-nuclear.

Tabela 8. Resultados do teste de discriminação com estímulos referentes ao pré-núcleo entoacional, confrontando dados de Florianópolis (Fpolis) e Porto Alegre (POA).

\begin{tabular}{l|l|l}
\hline Estímulos & Igual & Diferente \\
\hline Fpolis - Ox - Decl $x$ POA - Ox - Decl & $31 \%$ & $69 \%$ \\
\hline Fpolis - Ox - Int $x$ POA - Ox - Decl & $8 \%$ & $92 \%$ \\
\hline POA - Ox - Int $x$ POA - Ox - Decl & $69 \%$ & $31 \%$ \\
\hline Fpolis - Pro - Int $x$ POA - Pro - Int & $39 \%$ & $61 \%$ \\
\hline Fpolis - Pro - Int $x$ Fpolis - Pro - Decl & $69 \%$ & $31 \%$ \\
\hline POA - Pro - Int $x$ Fpolis - Pro - Int & $8 \%$ & $92 \%$ \\
\hline POA - Pro - Int $x$ POA - Pro - Decl & $69 \%$ & $31 \%$ \\
\hline
\end{tabular}

Fonte: Elaboração própria 
A partir da Tabela 8, verificamos que, quando havia confronto entre declarativas e interrogativas de uma mesma variedade, elas eram percebidas como iguais. Observamos, no entanto, que os resultados que confrontavam dados de Florianópolis e Porto Alegre não foram os esperados, haja vista as diferenças indicadas pelos ouvintes nas regiões pré-nucleares de sentenças declarativas neutras e interrogativas totais nessas duas variedades dialetais. Nesse caso, os percentuais variaram entre $61 \%$ e $92 \%$. De forma geral, os resultados concernentes às três capitais corroboram também os dados de produção descritos anteriormente. Pela Figura 10, que sobrepõe as curvas de F0 de sentenças declarativas e interrogativas de uma mesma variedade, é possível verificar que há uma distância (em st) no pré-núcleo dessas sentenças bastante evidente para a variedade de Curitiba e não há uma distância considerável para as variedades de Florianópolis e Porto Alegre, que se aproximam no seu movimento.

Decidimos também avaliar em separado os resultados desse teste de discriminação em função das variedades dos ouvintes. Assim, na Tabela 9, conseguimos distribuir os ouvintes em florianopolitanos, porto alegrenses, outras cidades de Santa Catarina e outras cidades do Rio Grande do Sul?

7 Lembramos que havia um ouvinte curitibano que foi descartado em função das respostas dadas aos pares de estímulos iguais. 
- A variação na entoação de declarativas neutras e interrogativas totais nas três capitais do Sul do Brasil

Tabela 9. Resultados do teste de discriminação com estímulos referentes ao pré-núcleo entoacional, considerando a variedade dos ouvintes.

\begin{tabular}{|c|c|c|c|c|c|c|c|c|}
\hline \multirow{2}{*}{ Estímulos } & \multicolumn{2}{|c|}{ Florianópolis } & \multicolumn{2}{|c|}{ Porto Alegre } & \multicolumn{2}{|c|}{ SC } & \multicolumn{2}{|c|}{$\mathbf{R S}^{8}$} \\
\hline & $=$ & $\neq$ & $=$ & $\neq$ & $=$ & $\neq$ & $=$ & $\neq$ \\
\hline Curitiba - Ox - Int $x$ Curitiba - Ox - Decl & $50 \%$ & $50 \%$ & $0 \%$ & $100 \%$ & $25 \%$ & $75 \%$ & $0 \%$ & $100 \%$ \\
\hline Curitiba - Ox - Int $x$ Fpolis - Ox - Int & $0 \%$ & $100 \%$ & $0 \%$ & $100 \%$ & $0 \%$ & $100 \%$ & $0 \%$ & $100 \%$ \\
\hline Curitiba - Ox - Decl $x$ Fpolis - Ox - Decl & $25 \%$ & $75 \%$ & $0 \%$ & $100 \%$ & $0 \%$ & $100 \%$ & $0 \%$ & $100 \%$ \\
\hline Curitiba - Ox - Decl $x$ POA - Ox - Decl & $25 \%$ & $75 \%$ & $50 \%$ & $50 \%$ & $0 \%$ & $100 \%$ & $0 \%$ & $100 \%$ \\
\hline Curitiba - Ox - Int $x$ Fpolis - Ox - Int & $0 \%$ & $100 \%$ & $0 \%$ & $100 \%$ & $0 \%$ & $100 \%$ & $0 \%$ & $100 \%$ \\
\hline Curitiba - Ox - Int $x$ POA - Ox - Int & $0 \%$ & $100 \%$ & $0 \%$ & $100 \%$ & $25 \%$ & $75 \%$ & $0 \%$ & $100 \%$ \\
\hline Curitiba - Pro - Int $x$ POA - Pro - Int & $0 \%$ & $100 \%$ & $0 \%$ & $100 \%$ & $0 \%$ & $100 \%$ & $0 \%$ & $100 \%$ \\
\hline Curitiba - Pro - Int $x$ Fpolis - Pro - Int & $0 \%$ & $100 \%$ & $0 \%$ & $100 \%$ & $25 \%$ & $75 \%$ & $0 \%$ & $100 \%$ \\
\hline POA - Ox - Int $x$ Curitiba - Ox - Int & $0 \%$ & $100 \%$ & $0 \%$ & $100 \%$ & $25 \%$ & $75 \%$ & $0 \%$ & $100 \%$ \\
\hline Fpolis - Ox - Decl $x$ POA - Ox - Decl & $50 \%$ & $50 \%$ & $0 \%$ & $100 \%$ & $25 \%$ & $75 \%$ & $0 \%$ & $100 \%$ \\
\hline Fpolis - Ox - Int $x$ POA - Ox - Decl & $0 \%$ & $100 \%$ & $0 \%$ & $100 \%$ & $25 \%$ & $75 \%$ & $0 \%$ & $100 \%$ \\
\hline Fpolis - Pro - Int $x$ POA - Pro - Int & $50 \%$ & $50 \%$ & $50 \%$ & $50 \%$ & $25 \%$ & $75 \%$ & $100 \%$ & $0 \%$ \\
\hline POA - Pro - Int $x$ Fpolis - Pro - Int & $0 \%$ & $100 \%$ & $0 \%$ & $100 \%$ & $25 \%$ & $75 \%$ & $0 \%$ & $100 \%$ \\
\hline Fpolis - Pro - Int $x$ Fpolis - Pro - Decl & $75 \%$ & $25 \%$ & $50 \%$ & $50 \%$ & $100 \%$ & $0 \%$ & $100 \%$ & $0 \%$ \\
\hline $\mathrm{POA}-\mathrm{Ox}-\operatorname{Int} x \mathrm{POA}-\mathrm{Ox}-\mathrm{Decl}$ & $75 \%$ & $25 \%$ & $50 \%$ & $50 \%$ & $75 \%$ & $25 \%$ & $100 \%$ & $0 \%$ \\
\hline POA - Pro - Int $x$ POA - Pro - Decl & $75 \%$ & $25 \%$ & $50 \%$ & $50 \%$ & $75 \%$ & $25 \%$ & $100 \%$ & $0 \%$ \\
\hline
\end{tabular}

Fonte: Elaboração própria

Novamente, observando os dados dos ouvintes distribuídos por suas variedades, percebe-se que as produções de Curitiba em confronto com produções das duas outras capitais foram percebidas majoritariamente como diferentes (veja os percentuais em negrito). Em contrapartida, nas produções de Florianópolis em confronto com Porto Alegre, ou declarativas confrontadas com interrogativas de uma mesma variedade, considerandose ouvintes florianopolitanos, não foi observado um comportamento recorrente. Para ouvintes catarinenses, quando confrontados dados de Florianópolis e Porto Alegre, foram considerados diferentes e quando confrontados dados de uma mesma variedade, não houve tendência. Nas produções de Porto Alegre em confronto com Florianópolis, ou declarativas confrontadas com interrogativas de uma mesma variedade, considerandose ouvintes porto alegrenses, dados de florianopolitanos confrontados com dados de porto alegrenses, ou vice-versa, foram considerados majoritariamente diferentes e quando foram comparados dados de uma mesma variedade não houve tendência. Para os gaúchos, o confronto entre dados de Florianópolis e Porto Alegre foram considerados

8 Os resultados referentes ao Rio Grande do Sul são relativos a um único informante, dessa forma, deve ser considerado com cautela. 
majoritariamente diferentes e de uma mesma variedade majoritariamente iguais. Esses dados também parecem corroborar os resultados acústicos já apresentados.

O segundo teste de percepção aplicado foi o de identificação. Os resultados referentes a dados do pré-núcleo e núcleo entoacionais são mostrados nas Tabelas 10 e 11, respectivamente. Considerando-se as descobertas exibidas nos resultados dos experimentos de produção, o que esperávamos com este teste era que, quando os sujeitos ouvissem dados referentes ao pré-núcleo de curitibanos, identificassem as declarativas e interrogativas adequadamente, haja vista a diferença salientada pelos valores bem acima dos 3 st. Já quando os dados referentes às produções de porto alegrenses e florianopolitanos fossem confrontados, que houvesse menos acertos e mais respostas não sei em função das semelhanças encontradas entre declarativas e interrogativas para essas duas variedades, já evidenciadas pelo teste de discriminação.

Tabela 10. Resultados do teste de identificação com estímulos referentes ao pré-núcleo entoacional

\begin{tabular}{l|l|l|l|l}
\hline Estímulos & Interrogativa & Declarativa & Não sei & Resposta esperada \\
\hline Fpolis - Ox - Decl & $64 \%$ & $36 \%$ & $0 \%$ & Declarativa \\
\hline Fpolis - Par - Decl & $29 \%$ & $71 \%$ & $0 \%$ & Declarativa \\
\hline Fpolis - Ox - Int & $64 \%$ & $36 \%$ & $0 \%$ & Interrogativa \\
\hline Fpolis - Par - Int & $43 \%$ & $57 \%$ & $0 \%$ & Interrogativa \\
\hline Curitiba - Ox - Decl & $43 \%$ & $43 \%$ & $14 \%$ & Declarativa \\
\hline Curitiba - Par - Decl & $86 \%$ & $14 \%$ & $0 \%$ & Declarativa \\
\hline Curitiba - Ox - Int & $57 \%$ & $36 \%$ & $7 \%$ & Interrogativa \\
\hline Curitiba - Par - Int & $43 \%$ & $50 \%$ & $7 \%$ & Interrogativa \\
\hline POA - Ox - Decl & $36 \%$ & $57 \%$ & $7 \%$ & Declarativa \\
\hline POA - Par - Decl & $36 \%$ & $57 \%$ & $7 \%$ & Declarativa \\
\hline POA - Ox - Int & $7 \%$ & $79 \%$ & $14 \%$ & Interrogativa \\
\hline POA - Par - Int & $29 \%$ & $64 \%$ & $7 \%$ & Interrogativa \\
\hline
\end{tabular}

Fonte: Elaboração própria

Os resultados referentes ao pré-núcleo mostraram que, para os estímulos de florianopolitanos, não houve resposta não sei, aparecendo, entretanto, com frequência nas respostas aos estímulos de curitibanos e porto alegrenses. Nesse caso, esperávamos que o número de respostas não sei fossem as mais evidentes, uma vez que as informações acústicas nessa região da sentença não apresentam grande saliência prosódica. 
- A variação na entoação de declarativas neutras e interrogativas totais nas três capitais do Sul do Brasil

De maneira geral, apenas 31\% das identificações dos estímulos foram adequadas ${ }^{9}$. Acreditamos que as razões para esse comportamento podem estar também relacionadas às variedades dos ouvintes que fizeram os testes, haja vista que, dentre eles, não havia nenhum curitibano, ao passo que tínhamos florianopolitanos e porto alegrenses e de outras variedades catarinenses e gaúchas. Para verificarmos se há indícios de que a variedade dialetal possa interferir nessa identificação, dividimos as respostas em função das variedades dos ouvintes. Observe o resultado na Tabela 11.

Tabela 11. Resultados do teste de identificação com estímulos referentes ao pré-núcleo entoacional, considerando a variedade dos ouvintes

\begin{tabular}{l|l|l|l|l|l|l|l|l|l|l|l|l}
\hline \multirow{2}{*}{ Estímulos } & \multicolumn{3}{|c|}{ Florianópolis } & \multicolumn{3}{c|}{ Porto Alegre } & \multicolumn{3}{c|}{ SC } & \multicolumn{3}{c}{ RS $^{10}$} \\
\cline { 2 - 14 } & int. & decl. & n. sei & int. & decl. & n. sei & int. & decl. & n. sei & int. & decl. & n. sei \\
\hline Fpolis-ox-decl & $50 \%$ & $50 \%$ & $0 \%$ & $0 \%$ & $100 \%$ & $0 \%$ & $75 \%$ & $25 \%$ & $0 \%$ & $100 \%$ & $0 \%$ & $0 \%$ \\
\hline $\begin{array}{l}\text { Fpolis-par- } \\
\text { decl }\end{array}$ & $50 \%$ & $50 \%$ & $0 \%$ & $0 \%$ & $100 \%$ & $0 \%$ & $25 \%$ & $75 \%$ & $0 \%$ & $0 \%$ & $100 \%$ & $0 \%$ \\
\hline Fpolis-ox-int & $25 \%$ & $75 \%$ & $0 \%$ & $100 \%$ & $0 \%$ & $0 \%$ & $100 \%$ & $0 \%$ & $0 \%$ & $100 \%$ & $0 \%$ & $0 \%$ \\
\hline Fpolis-par-int & $25 \%$ & $75 \%$ & $0 \%$ & $50 \%$ & $50 \%$ & $0 \%$ & $75 \%$ & $25 \%$ & $0 \%$ & $0 \%$ & $100 \%$ & $0 \%$ \\
\hline Cur_ox_decl & $50 \%$ & $25 \%$ & $25 \%$ & $50 \%$ & $50 \%$ & $0 \%$ & $25 \%$ & $50 \%$ & $25 \%$ & $100 \%$ & $0 \%$ & $0 \%$ \\
\hline Cur_par_decl & $100 \%$ & $0 \%$ & $0 \%$ & $100 \%$ & $0 \%$ & $0 \%$ & $50 \%$ & $50 \%$ & $0 \%$ & $100 \%$ & $0 \%$ & $0 \%$ \\
\hline Cur_ox_int & $50 \%$ & $50 \%$ & $0 \%$ & $0 \%$ & $50 \%$ & $50 \%$ & $25 \%$ & $75 \%$ & $0 \%$ & $100 \%$ & $0 \%$ & $0 \%$ \\
\hline Cur-par_int & $75 \%$ & $0 \%$ & $25 \%$ & $50 \%$ & $50 \%$ & $0 \%$ & $25 \%$ & $75 \%$ & $0 \%$ & $0 \%$ & $100 \%$ & $0 \%$ \\
\hline Poa_ox_decl & $0 \%$ & $75 \%$ & $25 \%$ & $0 \%$ & $100 \%$ & $0 \%$ & $75 \%$ & $25 \%$ & $0 \%$ & $0 \%$ & $100 \%$ & $0 \%$ \\
\hline Poa_par_decl & $25 \%$ & $75 \%$ & $0 \%$ & $0 \%$ & $50 \%$ & $50 \%$ & $25 \%$ & $75 \%$ & $0 \%$ & $100 \%$ & $0 \%$ & $0 \%$ \\
\hline Poa_ox_int & $0 \%$ & $75 \%$ & $25 \%$ & $0 \%$ & $50 \%$ & $50 \%$ & $0 \%$ & $100 \%$ & $0 \%$ & $0 \%$ & $100 \%$ & $0 \%$ \\
\hline Poa_par_int & $0 \%$ & $75 \%$ & $25 \%$ & $0 \%$ & $100 \%$ & $0 \%$ & $50 \%$ & $50 \%$ & $0 \%$ & $0 \%$ & $100 \%$ & $0 \%$ \\
\hline
\end{tabular}

Fonte: Elaboração própria

De forma geral, observamos que, também separados por suas variedades, os percentuais de acerto para florianopolitanos, curitibanos e porto alegrenses foram baixos. Verificamos ainda que os estímulos dos curitibanos, independentemente de serem prénúcleos de declarativas ou de interrogativas, foram considerados pela maior parte dos ouvintes como interrogativos. Já os de porto alegrenses foram considerados em sua maioria como declarativos. Esses resultados podem estar relacionados às diferenças em semitons observadas entre sentenças declarativas e interrogativas produzidas por curitibanos. Observe a Figura 11.

9 Nas Tabelas 10, 11, 12 e 13, os percentuais de respostas que corresponderam às respostas esperadas estão assinalados em cinza escuro.

10 Os resultados referentes ao Rio Grande do Sul são relativos a um único informante, dessa forma deve ser considerado com cautela. 
Figura 11. Sobreposição de estímulos utilizados no teste de identificação relativos ao pré-núcleo entonacional de sentenças declarativas e interrogativas das três capitais
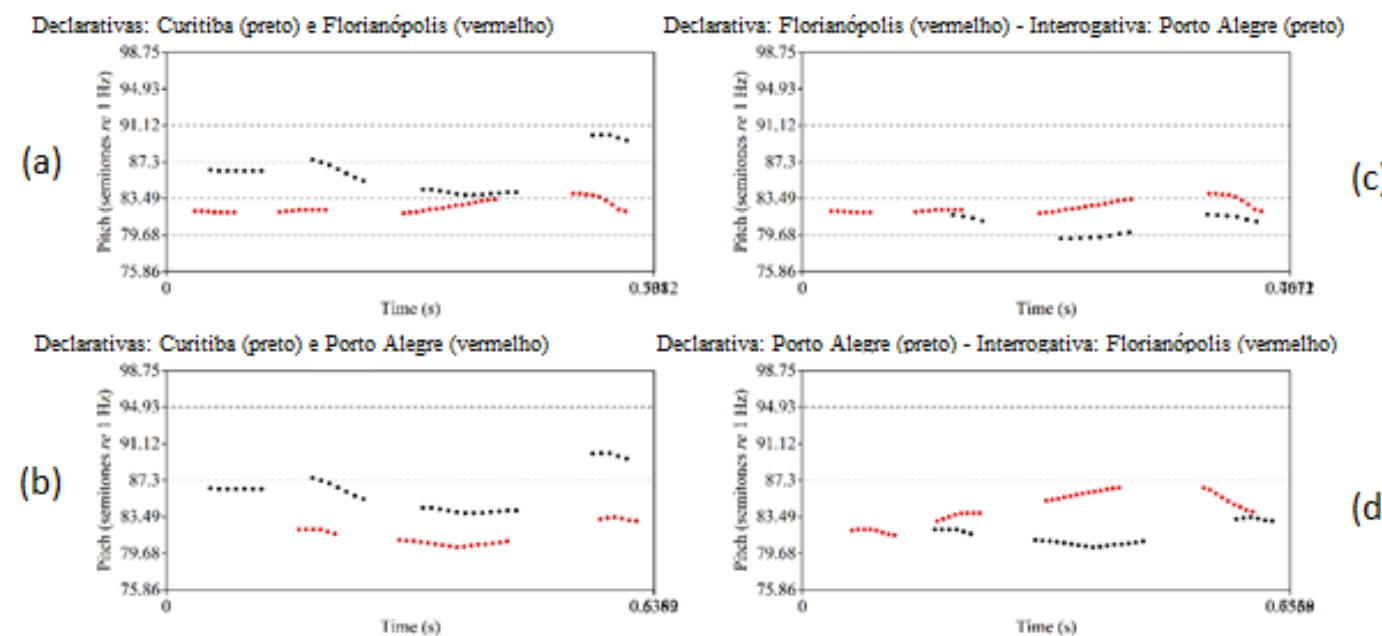

Fonte: Elaboração própria

Na Figura 11, em (a), observamos a sobreposição das curvas de F0 de sentenças declarativas de Curitiba (preto) e de Florianópolis (vermelho). Em (b), vemos a sobreposição das curvas de F0 de declarativas de Curitiba (preto) e de Porto Alegre (vermelho). Em (c), verificamos a sobreposição de sentença declarativa de Florianópolis (vermelho) e de interrogativa de Porto Alegre (preto) e, em (d), temos a sobreposição e sentença interrogativa de Florianópolis (vermelho) e declarativa de Porto Alegre (preto).

Observamos, então, pela Figura 11, que parece haver uma maior variação de F0 entre declarativas produzidas por falantes de Curitiba e Florianópolis (em (a)) e entre falantes de Curitiba e Porto Alegre (em (b)). Essa variação se assemelha àquela encontrada entre declarativas e interrogativas produzidas por falantes de Florianópolis e Porto Alegre, conforme pode se constatar na Figura 11(c) e (d). Desse modo, acreditamos que os erros em relação aos estímulos dos curitibanos tenham ocorrido justamente por conta da grande saliência de F0 também nas declarativas, o que levava florianopolitanos e porto alegrenses a acharem o estímulo interrogativo. Os resultados do teste de identificação reforçam esse comportamento, pois considerando a saliência prosódica das interrogativas, as declarativas de curitibanos, que apresentavam valores altos de F0, foram também percebidas como interrogativas.

Para os erros apresentados em relação aos estímulos de porto alegrenses, achamos que, ao contrário do que se viu anteriormente, aqui é a menor saliência de F0 e um movimento final semelhante entre declarativas de porto alegrenses e de florianopolitanos 
- A variação na entoação de declarativas neutras e interrogativas totais nas três capitais do Sul do Brasil

que talvez tenha levado os ouvintes florianopolitanos e porto alegrenses a consideraram pré-núcleos interrogativos como declarativos. Observe a Figura 11(c) e (d).

Agora, passemos aos resultados concernentes ao núcleo entonacional. Pela Tabela 12 , inferimos que a maior parte das respostas foi adequada, o que era esperado uma vez que é, principalmente, no núcleo entonacional que são marcadas as diferenças entre as modalidades declarativa neutra e interrogativa total. Essas diferenças foram também bastante evidentes nos dados acústicos aqui analisados. Pela Tabela 12, constata-se que agora as respostas não sei ocorrem para a maioria dos estímulos, embora com baixa percentagem.

Tabela 12. Resultados do teste de identificação com estímulos referentes ao núcleo entoacional

\begin{tabular}{l|l|l|l|l}
\hline Estímulos & Interrogativa & Declarativa & Não sei & Resposta esperada \\
\hline Fpolis - Ox - Decl & $36 \%$ & $64 \%$ & $0 \%$ & Declarativa \\
\hline Fpolis - Par - Decl & $36 \%$ & $57 \%$ & $7 \%$ & Declarativa \\
\hline Fpolis - Ox - Int & $36 \%$ & $57 \%$ & $7 \%$ & Interrogativa \\
\hline Fpolis - Par - Int & $22 \%$ & $64 \%$ & $14 \%$ & Interrogativa \\
\hline Curitiba - Ox - Decl & $29 \%$ & $64 \%$ & $7 \%$ & Declarativa \\
\hline Curitiba - Par - Decl & $71 \%$ & $22 \%$ & $7 \%$ & Declarativa \\
\hline Curitiba - Ox - Int & $100 \%$ & 00 & $0 \%$ & Interrogativa \\
\hline Curitiba - Par - Int & $93 \%$ & 00 & $7 \%$ & Interrogativa \\
\hline POA - Ox - Decl & $29 \%$ & $71 \%$ & $0 \%$ & Declarativa \\
\hline POA - Par - Decl & $7 \%$ & $79 \%$ & $14 \%$ & Declarativa \\
\hline POA - Ox - Int & $71 \%$ & $22 \%$ & $7 \%$ & Interrogativa \\
\hline POA - Par - Int & $21 \%$ & $79 \%$ & $0 \%$ & Interrogativa \\
\hline
\end{tabular}

Fonte: Elaboração própria

Verificamos, ainda pela Tabela 12, que os estímulos declarativos foram mais bem percebidos do que os interrogativos. Nossa expectativa era a de que os estímulos interrogativos fossem mais bem percebidos, uma vez que apresentam mais saliência prosódica. No entanto, os estímulos que constituíam as variedades que haviam apresentado valores mais altos de F0 mostraram respostas mais consistentes, como os estímulos referentes aos curitibanos que foram identificados adequadamente, com maior acurácia para as interrogativas. Os estímulos dos porto alegrenses também apresentaram respostas adequadas, mostrando, no entanto, maior acurácia para os estímulos declarativos, como também ocorreu para os estímulos declarativos dos florianopolitanos. Acreditamos que os erros referentes às interrogativas de Florianópolis e Porto Alegre se devam a diferenças menos salientes entre declarativas e interrogativas nessas duas variedades, diferentemente do que ocorre com a variedade de Curitiba. 
Considerando-se ainda que a variedade dos ouvintes possa condicionar as respostas dos testes de identificação, apresentamos, também aqui, os resultados a partir da distribuição apresentada na Tabela 13.

Tabela 13. Resultados do teste de identificação com estímulos referentes ao núcleo entoacional, considerando a variedade dos ouvintes

\begin{tabular}{l|l|l|l|l|l|l|l|l|l|l|l|l}
\hline \multirow{2}{*}{ Estímulos } & \multicolumn{3}{|c|}{ Florianópolis } & \multicolumn{3}{c|}{ Porto Alegre } & \multicolumn{3}{c}{ SC } & \multicolumn{3}{c}{ RS } \\
\cline { 2 - 13 } & int. & decl. & n. sei & int. & decl. & n. sei & int. & decl. & n. sei & int. & decl. & n. sei \\
\hline Fpolis-ox-decl & $25 \%$ & $75 \%$ & $0 \%$ & $50 \%$ & $50 \%$ & $0 \%$ & $25 \%$ & $75 \%$ & $0 \%$ & $0 \%$ & $100 \%$ & $0 \%$ \\
\hline $\begin{array}{l}\text { Fpolis-par- } \\
\text { decl }\end{array}$ & $50 \%$ & $50 \%$ & $0 \%$ & $0 \%$ & $100 \%$ & $0 \%$ & $25 \%$ & $50 \%$ & $25 \%$ & $0 \%$ & $100 \%$ & $0 \%$ \\
\hline Fpolis-ox-int & $75 \%$ & $25 \%$ & $0 \%$ & $50 \%$ & $0 \%$ & $50 \%$ & $0 \%$ & $100 \%$ & $0 \%$ & $0 \%$ & $100 \%$ & $0 \%$ \\
\hline Fpolis-par-int & $25 \%$ & $50 \%$ & $25 \%$ & $50 \%$ & $50 \%$ & $0 \%$ & $0 \%$ & $75 \%$ & $25 \%$ & $0 \%$ & $100 \%$ & $0 \%$ \\
\hline Cur_ox_decl & $25 \%$ & $50 \%$ & $25 \%$ & $0 \%$ & $100 \%$ & $0 \%$ & $25 \%$ & $75 \%$ & $0 \%$ & $100 \%$ & $0 \%$ & $0 \%$ \\
\hline Cur_par_decl & $50 \%$ & $25 \%$ & $25 \%$ & $50 \%$ & $50 \%$ & $0 \%$ & $100 \%$ & $0 \%$ & $0 \%$ & $100 \%$ & $0 \%$ & $0 \%$ \\
\hline Cur_ox_int & $100 \%$ & $0 \%$ & $0 \%$ & $100 \%$ & $0 \%$ & $0 \%$ & $100 \%$ & $0 \%$ & $0 \%$ & $100 \%$ & $0 \%$ & $0 \%$ \\
\hline Cur-par_int & $100 \%$ & $0 \%$ & $0 \%$ & $100 \%$ & $0 \%$ & $0 \%$ & $75 \%$ & $0 \%$ & $25 \%$ & $100 \%$ & $0 \%$ & $0 \%$ \\
\hline Poa_ox_decl & $25 \%$ & $75 \%$ & $0 \%$ & $0 \%$ & $100 \%$ & $0 \%$ & $25 \%$ & $75 \%$ & $0 \%$ & $100 \%$ & $0 \%$ & $0 \%$ \\
\hline Poa_par_decl & $0 \%$ & $75 \%$ & $25 \%$ & $0 \%$ & $50 \%$ & $50 \%$ & $0 \%$ & $100 \%$ & $0 \%$ & $100 \%$ & $0 \%$ & $0 \%$ \\
\hline Poa_ox_int & $50 \%$ & $25 \%$ & $25 \%$ & $50 \%$ & $50 \%$ & $0 \%$ & $75 \%$ & $25 \%$ & $0 \%$ & $100 \%$ & $0 \%$ & $0 \%$ \\
\hline Poa_par_int & $25 \%$ & $75 \%$ & $0 \%$ & $0 \%$ & $100 \%$ & $0 \%$ & $25 \%$ & $75 \%$ & $0 \%$ & $100 \%$ & $0 \%$ & $0 \%$ \\
\hline
\end{tabular}

Fonte: Elaboração própria

Pela Tabela 13, constatamos que os estímulos interrogativos de curitibanos foram os que obtiveram os percentuais mais elevados, variando de $75 \%$ a $100 \%$, independentemente da variedade do ouvinte. No entanto, quando observamos os estímulos de núcleos interrogativos de porto alegrenses e florianopolitanos, os resultados foram bastante incipientes. Novamente, inferimos que é a maior saliência de F0 das interrogativas de curitibanos que corroboram esses resultados. E, no caso dos estímulos de porto alegrenses e florianopolitanos, observa-se o inverso, ou seja, uma menor saliência de F0 das interrogativas dessas variedades faz com que sejam percebidas como declarativas. Observe a Figura 12. 
- A variação na entoação de declarativas neutras e interrogativas totais nas três capitais do Sul do Brasil

Figura 12. Sobreposição de estímulos utilizados no teste de identificação relativos ao núcleo entonacional de declarativas e interrogativas das três capitais do Sul do Brasil

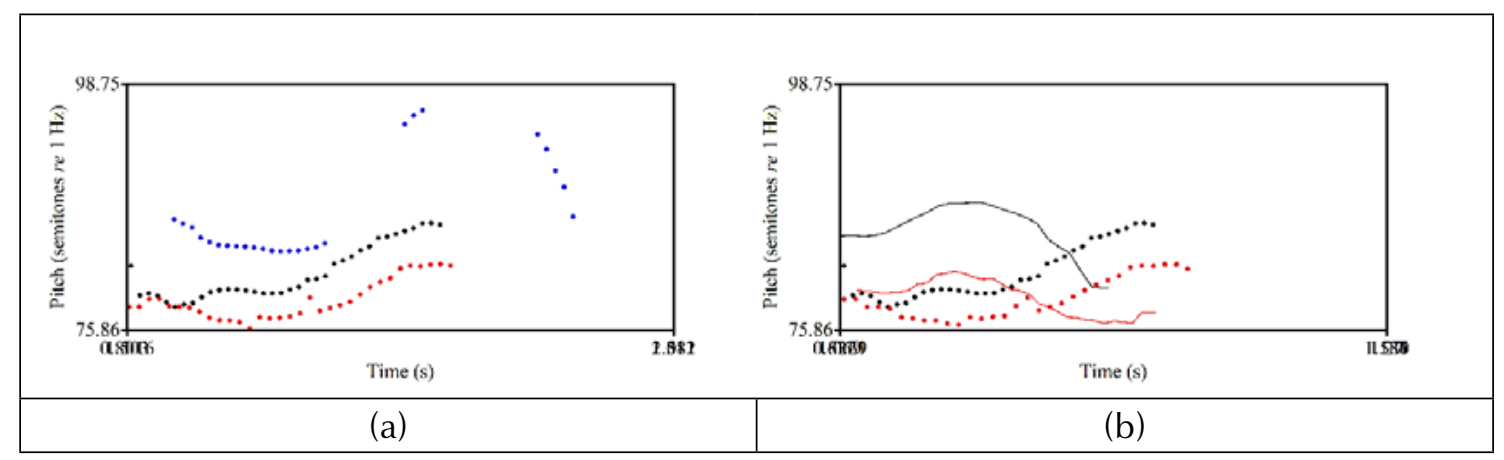

Fonte: Elaboração própria

Na Figura 12 (a), temos a sobreposição de dados de núcleos de sentenças interrogativas de Curitiba (azul), de Florianópolis (preto) e de Porto Alegre (vermelho). Já na Figura 12 (b), vemos a sobreposição de dados de núcleos de sentenças declarativa (linha preta contínua) e interrogativa (linha preta pontilhada) de Florianópolis e declarativa (linha vermelha contínua) e interrogativa (linha vermelha pontilhada) de Porto Alegre.

Na Figura 12 (a), é possível perceber a saliência prosódica anteriormente discutida entre dados produzidos por curitibanos (azul) e das duas outras variedades (preto e vermelho). Já na Figura 12(b), são mostrados dados de núcleos declarativos e interrogativos de produções de florianopolitanos (preto) e porto alegrenses (vermelho) e nota-se a menor saliência entre as duas modalidades e entre elas e os dados de curitibanos, se compararmos a Figura 12(a) com 12(b). Assim, julgamos que os erros e acertos, anteriormente descritos, se devem a esse comportamento das curvas de FO.

Feitas essas análises, passemos às considerações finais.

\section{Considerações finais e perspectivas de trabalho futuro}

Finalmente, respondendo às nossas questões de pesquisa, constatamos que os resultados dos experimentos de produção foram, de certa maneira, ratificados pelos experimentos de percepção. Quer dizer: verificamos diferenças no pré-núcleo e no núcleo entoacional entre curitibanos e as demais variedades com diferenças de mais de 3 st e também entre declarativas e interrogativas de curitibanos. Essas diferenças foram percebidas pelos ouvintes. Observamos ainda que, quando confrontados dados de florianopolitanos e porto alegrenses, foram percebidas diferenças. No entanto, quando confrontados dados de interrogativas e declarativas de uma mesma variedade (Florianópolis ou Porto Alegre), não foram notadas diferenças. 
Salientamos que este é o primeiro resultado que apresentamos sobre as três capitais em conjunto e que serão necessárias outras análises relacionadas também ao desenho da curva de F0 e à tessitura, parâmetros já observados por Nunes (2015) para o falar florianopolitano e Milan (2015) para o falar curitibano. Assim, apesar de esses resultados já mostrarem uma certa robustez, assinalada pelos resultados objetivos e pelos testes de percepção, devem ser lidos com alguma cautela, visto que precisamos também considerar os resultados às sentenças com um número maior de vogais, estruturas já previstas pelo Projeto AMPER-POR, e dos quais, neste momento, não dispomos ainda dos resultados acústicos. Além disso, será ainda necessário incluir um maior número de produções, bem como um maior número de ouvintes e, sobretudo, proceder também a um maior controle das variedades faladas pelos ouvintes dos testes de percepção. O alargamento dos dados contemplados possibilitará a realização de testes estatísticos, importantes para este tipo de estudo.

\section{Referências}

AMPER-POR. Atlas Multimídia Prosódico do Espaço Românico: Língua Portuguesa. Informações disponíveis em: http://www.varialing.eu/?page_id=704. Acesso em: 14 jun. 2016.

BOERSMA, P.; WEENINK, D. Praat v.6.0.19, 2016. Disponível em: www.praat.org. Acesso em: 14 jun. 2016.

BOTASSINI, J. O. M. A variação no uso dos róticos em Porto Alegre. Estudos linguísticos, São Paulo, v. 40, n. 2, p. 1060-1072, 2011.

BIASIBETTI, A. P. C. S. Produção e percepção das fricativas sibilantes em Porto Alegre/

RS e Florianópolis/SC. 2018. Tese (Doutorado em Letras) - Escola de Humanidades, Pontifícia Universidade Católica, Porto Alegre, 2018.

BROD, L. M. A lateral nos falares florianopolitano (PB) e portuense (PE): casos de gradiência fônica. 2014. Tese (Doutorado em Linguística) - Centro de Comunicação e Expressão, Universidade Federal de Santa Catarina, Florianópolis, 2014.

CAMPOS, E. C. S. S. L.; BROD, L. M.; SEARA, I. C. Estudo de casos: os róticos em Maringá (PR) e Florianópolis (SC). Revista uox, v. 1, p. 82-95, 2013. 
- A variação na entoação de declarativas neutras e interrogativas totais nas três capitais do Sul do Brasil

CASTELO, J.; FROTA, S. Variação entoacional no Português do Brasil: uma análise fonológica do contorno nuclear em enunciados declarativos e interrogativos. Revista da Associação Portuguesa de Linguística, n. 1, p. 95-120, 2016.

CONSONI, F.; FERREIRA NETTO, W. A percepção de variação em semitons ascendentes em palavras isoladas no português brasileiro. In: Congresso Nacional de Fonética e Fonologia, 10.; Congresso Internacional de Fonética e Fonologia, 4., 2008, Niterói. Anais... Niterói: UFF, 2008. Disponível em: https://bit.ly/3aYc4vH. Acesso em: 10 jan. 2017.

CRUZ, R. C. F.; SEARA, I. C.; MOUTINHO, L. Intonation of Yes/No question in Portuguese: analysis of the relationship between intonation and lexical stress in the AMPER-POR corpus. Revista de Estudios Linguisticos Hispânicos, v. Anexos, n. 7, p. 3544, 2015.

CUNHA, C. Entoação regional do português do Brasil. 2000. Tese (Doutorado em Língua Portuguesa) - Faculdade de Letras, Universidade Federal do Rio de Janeiro, Rio de Janeiro, 2000.

FURLAN, O. A. Influência açoriana no português do Brasil em Santa Catarina. Florianópolis: Editora da UFSC, 1989.

LACERDA, L. A representação da identidade do "manezinho": entre a arte e a vida. 2013. Dissertação (Mestrado em Linguística) - Universidade Federal de Santa Catarina, Florianópolis, 2013.

KLUGE, D.; RAUBER, A.; RATO, A.; SANTOS, G. R. Percepção de sons de Língua estrangeira: questões metodológicas e o uso dos aplicativos praat e tp. Revista Letras, Curitiba, UFPR, n. 88, p. 171-188, 2013.

HAUPT, C.; SEARA, I. C. As fricativas posteriores: caracterização articulatória e acústica do /r/ em onset silábico. Revista Entrepalavras, v. 10, n. 1, p. 77-97, 2020.

MARTINS, M. V. M.; NETTO, W. F. Prosódia e escalas de frequência: um estudo em torno da escala de semitons. ReVEL, v. 8, n. 15, 2010. Disponível em: www.revel.inf.br. Acesso em: 14 jun. 2016. 
MILAN, P. Subsídios para uma análise prosódica do dialeto de Curitiba: contribuições ao projeto Amper-Por. 2015. Dissertação (Mestrado em Letras) - Setor de Ciências Humanas, Universidade Federal do Paraná, Curitiba, 2015.

MILAN, P.; KLUGE, D. C. Diferenças na região pré-nuclear entre sentenças assertivas e interrogativas do dialeto curitibano: produção e percepção. Cadernos de Estudos Linguísticos, Campinas, v. 59, n. 2, p. 289-316, 2017a.

MILAN, P.; KLUGE, D. C. O papel da frequência fundamental e da intensidade para distinguir enunciados interrogativos de afirmativos na região nuclear do dialeto curitibano. Signum [Londrina]: Estudos de Linguagem, v. 20, p. 265-292, 2017 b.

MORAES, J. A. The Pitch Accents in brazilian portuguese: analysis by synthesis. In: Fourth Conference on Speech Prosody. Proceedings of the Speech Prosody. Campinas: UNICAMP, 2008. p. 389-397.

MORAES, J. A. Intonation in brazilian portuguese. In: HIRST, D.; DI CRISTO A. (ed.). Intonation systems: a survey of twenty languages. Cambridge: Cambridge University Press, 1998. p. 179-194.

MOUTINHO, L.; SEARA, I. C. A presença dos Açores em duas comunidades de Florianópolis (SC): aspetos prosódico-entoacionais. Géolinguistique, v. 19, p. 1-19, 2019.

MOUTINHO, L. de C.; COIMBRA, R. L. Variação entoacional no português europeu no âmbito do AMPER-Por. Revista Intercâmbio, São Paulo: LAEL/PUC-SP, v. XXII, p. 95-105, 2010.

MOUTINHO, L. et al. Variação entoacional em três áreas dialectais de Portugal Continental. In: LAI, J. (ed.). Project AMPER - Atlas Multimédia Prosodique de I'Espace Roman. Géolinguistique, hors série n. ${ }^{\circ}$ 3, p. 19-37, 2005.

NUNES, V. G.; SEARA, I. C. Distinção de variedades dialetais e de modalidades através de contornos de regiões pré-nucleares: análises acústicas e perceptuais. Diadorim, Rio de Janeiro, v. 17, p. 34-51, 2015. 
- A variação na entoação de declarativas neutras e interrogativas totais nas três capitais do Sul do Brasil

NUNES, V. G. A prosódia de sentenças interrogativas totais nos falares catarinenses e sergipanos. 2015. Tese (Doutorado em Linguística) - Centro de Comunicação e Expressão, Universidade Federal de Santa Catarina, Florianópolis, 2015.

NUNES, V. G. Análises entonacionais de sentenças declarativas e interrogativas totais nos falares florianopolitano e lageano. 2011. Dissertação (Mestrado em Linguística) - Centro de Comunicação e Expressão, Universidade Federal de Santa Catarina, Florianópolis, 2011.

NUNES, V. G.; RILLIARD, A.; SEARA, I. C. Pistas prosódicas do falar catarinense: um estudo sobre interrogativas totais neutras. Revista Linguagem \& Ensino, v. 18, p. 251-274, 2015.

SEARA, I. C.; SILVA, M. C. F.; BERRI, A. A entoação do SN-Sujeito no PB falado em Florianópolis: sentenças declarativas e interrogativas totais. Revista Internacional de Linguística Iberoamericana, v. IX, p. 157-168, 2011.

$\mathrm{t}^{\prime} \mathrm{HART}$, J. Differential sensitivity to pitch distance, particularly in speech. Journal of Acoustical Society of America, 1981.

\section{Agradecimentos}

Agradecemos ao CNPq pela bolsa de pesquisa (processo n. 308066/20189) que também possibilitou a parceria com pesquisadores do Projeto AMPER-POR do Laboratório de Fonética da Universidade de Aveiro (Portugal), sediado no Departamento de Línguas e Culturas dessa universidade. 
COMO CITAR ESTE ARTIGO: SEARA, Izabel Christine; MOUTINHO, Lurdes de Castro. A variação na entoação de declarativas neutras e interrogativas totais nas três capitais do Sul do Brasil. Revista do GEL, v. 17, n. 2, p. 230-266, 2020. Disponível em: https://revistadogel.gel.org.br/

DOI: http://dx.doi.org/10.21165/gel.v17i2.2454

Submetido em: 03/08/2019 | Aceito em: 24/06/2020. 